NIPER- -498

) DE91 002217

\title{
MODELING OF ASPHALTENE AND WAX PRECIPITATION
}

Topical Report

By

Frank Chung

Partha Sarathi

Ray Jones

January 1991

Work Performed Under Cooperative Agreement No. DE-FC22-83FE60149

\author{
Prepared for \\ U.S. Department of Energy \\ Assistant Secretary for Fossil Energy
}

\author{
Jerry Casteel, Project Manager \\ Bartlesville Project Office \\ P.O. Box 1398 \\ Bartlesville, OK 74005
}

Prepared by

IIT Research Institute

National Institute for Petroleum and Energy Research

P.O. Box 2128

Bartlesville, OK 74005 
Introduction

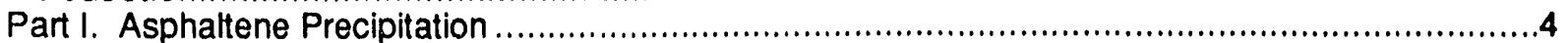

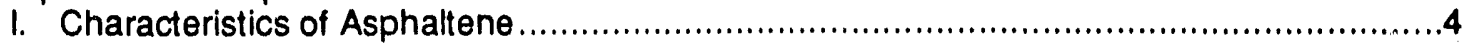

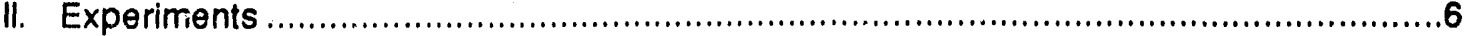

III. Modeling Asphaltene Precipitation in Oil Reservoir .............................................12

1. $C_{7}+$ Characterization .......................................................................... 13

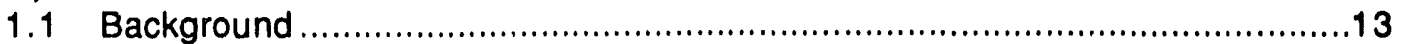

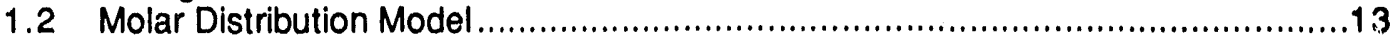

1.3 Gaussian Quadrature Method ......................................................... 14

1.4 Calculation Procedure......................................................................16

$1.5 C_{7}+$ Pseudocomponent Property Estimation.............................................17

I. Properities of the Reference System.............................................18

II. Properties of the Real System ......................................................18

2. Vapor-Liquid Equilibrium (VLE) Model...........................................................

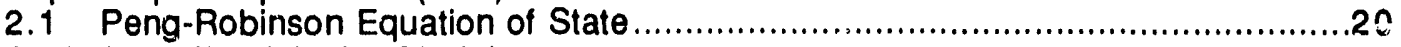

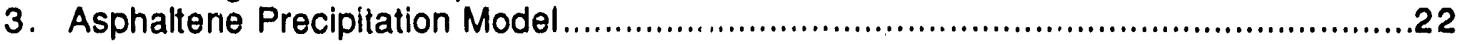

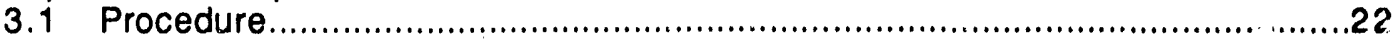

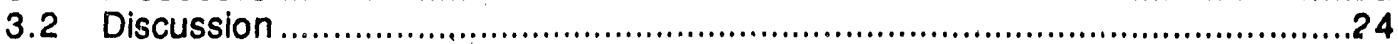

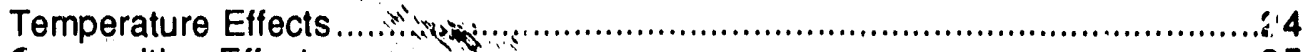

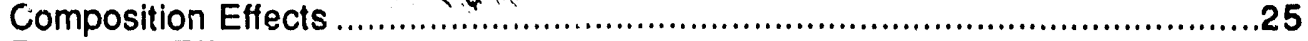

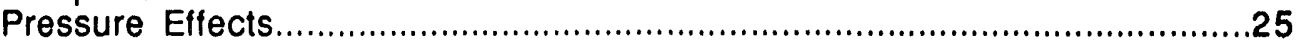

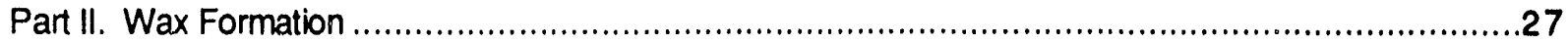

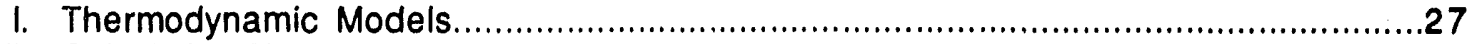

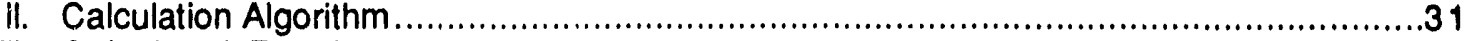

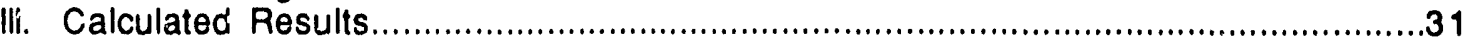

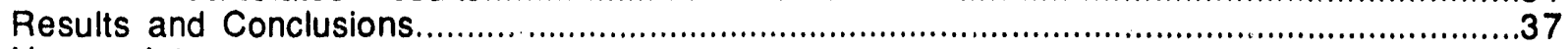

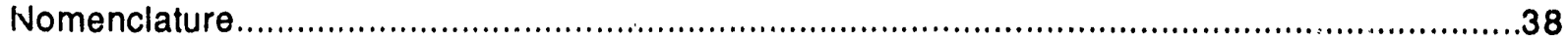

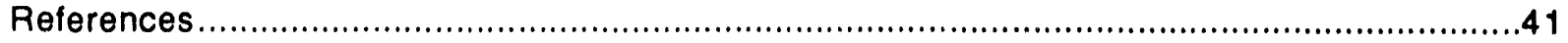

TABLES

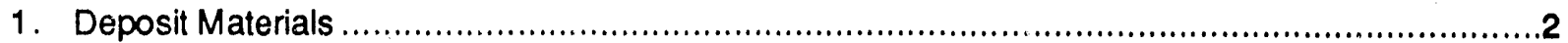

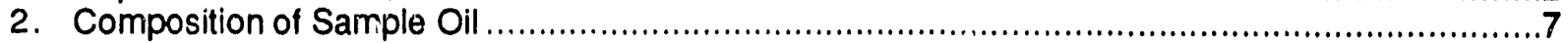

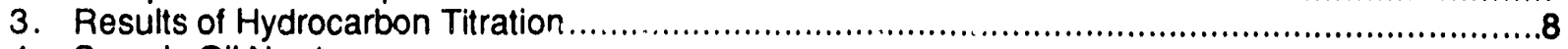

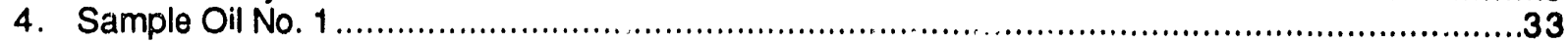

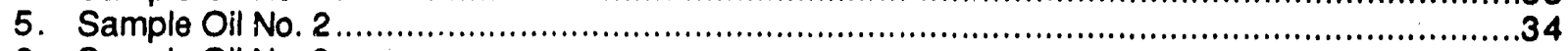

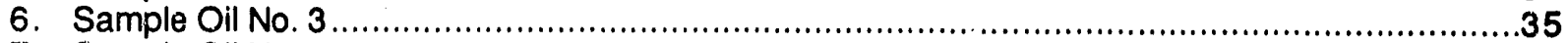

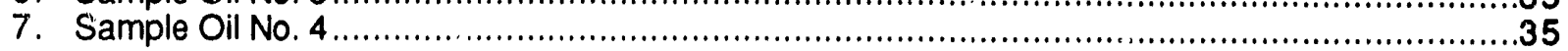

\section{ILLUSTRATIONS}

1. Amount of asphaltene precipitated by $n$-paraffin titration...................................................8

2. Precipitation of asphaltenes using different n-alkanes ..................................................

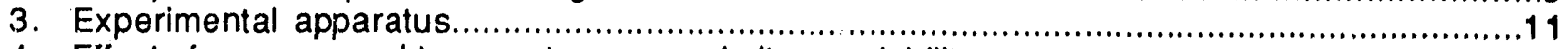

4. Effect of pressure and temperature on asphaltene solubility ...............................................25

5. Effect of composition on asphaltene solubility ................................................................26

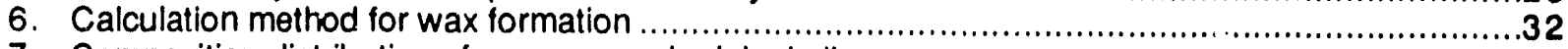

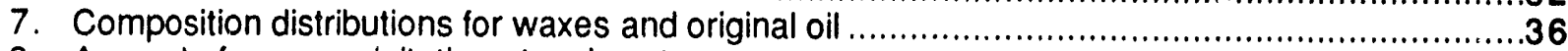

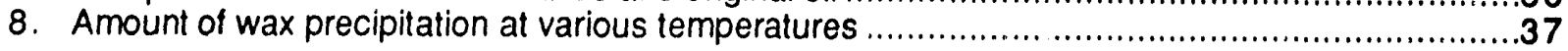


MODELING OF ASPHALTENE AND WAX PRECIPITATION

By

Frank Chung, Partha Sarathi, and Ray Jones

\begin{abstract}
Organic deposition has been shown to be a major problem associated with oil recovery by gas flooding. Industry is looking for ways of controlling organic deposition and economic methods that can remedy the problem. A predictive technique is crucial to the solution of this problem, and this research project was designed to focus on the development of a predictive technique. A thermodynamic model has been developed to describe the effects of temperature, pressure, and composition on asphaltene precipitation. The model employes a polymer solution theory for asphaltene-oil solution and treated asphaltene as a polydispersed medium. The proposed model combines regular solution theory with Flory-Huggins polymer solutions theory to predict maximum volume fractions of asphaltene dissolved in oil. The model requires evaluation of vapor-liquid equilibria, first using an equation of state followed by calculations of asphaltene solubility in the liquid-phase. A state-of-the-art technique for $\mathrm{C}_{7}+$ fraction characterization was employed in developing this model. The preliminary model developed in this work was able to predict qualitatively the trends of the effects of temperature, pressure, and composition. Since the mechanism of paraffinic wax deposition is different from that of asphaltene deposition, another thermodynamic model based on the solid-liquid solution theory was developed to predict the wax formation. This model is simple and can predict the wax appearance temperature with reasonable accuracy.

Accompanying the modeling work, experimental studies were conducted to investigate the solubility of asphaltene in oil and solvents and to examine the effects of oil composition, $\mathrm{CO}_{2}$, and solvent on asphaltene precipitation and its properties. This research focused on the solubility reversibility of asphaltene in oil and the precipitation caused by $\mathrm{CO}_{2}$ injection at simulated reservoir temperature and pressure conditions. These experiments have provided many observations about the properties of asphaitenes for further improvement of the model, but more detailed information about the properties of asphaltenes in solution is needed for the development of more reliable asphaltene characterization techniques.
\end{abstract}




\section{INTRODUCTION}

Organic deposition is a very common production problem which may occur during primary, secondary, and tertiary oil production. ${ }^{1-8}$ Deposition of organic matter in casing, production tubing, submersible pumps, and surface equipment results in operation difficulties and production decrease. Organic deposition matter is very complicated and may contain asphaltenes, asphaltic resins, wax, oil, solid, and wats. Table 1 shows the materials of two deposit samples obtained from the San Andres Unit of Seminole (TX) field in the Permian Basin. The field has been under tertiary $\mathrm{CO}_{2}$ flood.

The term asphaltene is frequently defined as the fraction of crude oil that is soluble in an aromatic solvent; for example, benzene, toluene, and xylene, but insoluble in light normal hydrocarbon solvents; (for example, pentane, heptane, and decane). The asphaltene fraction of crude oils typically consists of a mixture of polar ring aromatic and naphthenic molecules, which contain heteroatoms of nitrogen, sulfur, and oxygen. Molecular weight values vary widely depending upon the method of measurement. ${ }^{9-10}$ Asphaltenes are believed to exist in crude oil as colloidal particles which are suspended in crude oil by

TABLE 1. - Deposit materials

\begin{tabular}{|c|c|}
\hline \multicolumn{2}{|l|}{ CASING DEPOSIT } \\
\hline 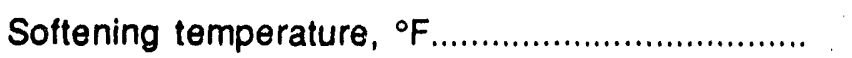 & $240-250$ \\
\hline 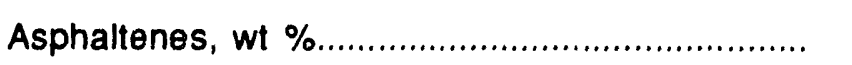 & 52.73 \\
\hline 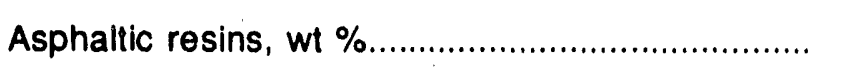 & 0.91 \\
\hline 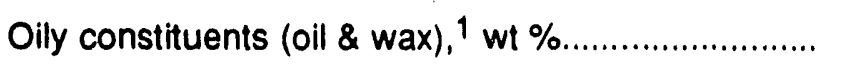 & 15.91 \\
\hline 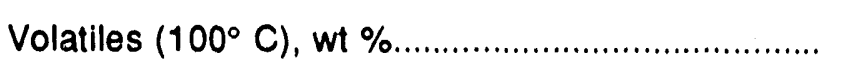 & 27.24 \\
\hline Solids, wt $\% \ldots . . . . . . . . . . . . .$. & 3.21 \\
\hline Water......................... & None \\
\hline \multicolumn{2}{|l|}{ TUBING DEPOSIT } \\
\hline 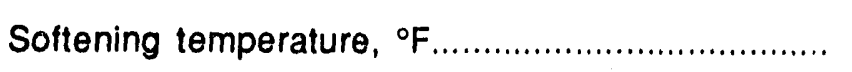 & $212-222$ \\
\hline 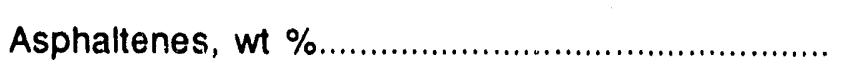 & 24.69 \\
\hline Asphaltic resins, wt \% & 1.57 \\
\hline Oily Constituents (oil \& $v^{\prime}$ ax), ${ }^{1}$ wt \%.......................... & 15.63 \\
\hline 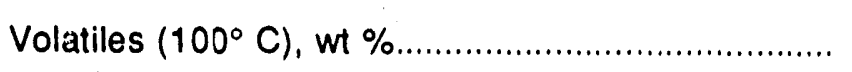 & 21.91 \\
\hline 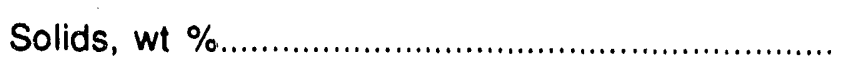 & 7.50 \\
\hline Water, wt \%.................. & 28.71 \\
\hline
\end{tabular}

1 Oily constituents - this is mostly $C_{10}$ to $C_{20}$; less than $1 \%$ was found to be paraffin of greater than $C_{20}$ chain length. 
peptizing agents. The resin fraction contains polar components which are soluble in $n$-pentane, $n$-heptane, toluene, and benzene but insoluble in ethylacetate at room temperature. ${ }^{11}$ Petroleum resins are adsorbable by a surface-active material such as Fuller's earth. The resin molecules are believed to stabilize the colloidal dispersions of asphaltene in crude sils by preventing aggregation of the asphaltene particles. ${ }^{12}$ Wax is high-molecular-weight paraffinic compounds which will crystallize at low temperatures. ${ }^{13}$

Asphaltene precipitation may occur when temperature, pressure, and chemical compositions of crude oil are changed. ${ }^{3,11}$ Electrical and other factors also influence asphaltene deposition. ${ }^{14-15}$ The use of hydrochloric acid for well stimulation can also cause formation damage by flocculation of the dispersion as asphaltic material. Asphaltene deposition is frequently associated with production of undersaturated reservoirs. In Hassi Messaoud field, ${ }^{8}$ problems with asphaltene deposition decreased when the pressure decreased below the bubble point. Lowering the pressure below the bubble point released gas from solution and resulted in two-phase flow in producing wells, which promoted peptization of the asphaltic material. In the Ula reservoir of the North Sea, deposition occurs over the tubing length corresponding to the pressures from 450 psi above the bubble point to the bubble point. Below the bubble point, no further deposition occurs because within this regime the rate of deposition reaches an equilibrium with the rate of erosion of deposited particles. ${ }^{1}$. Turbulence through two-phase flow will not allow efficient deposition. The asphaltene particles removed by erosion will accumulate ir separators.

Laboratory studies have indicated that carbon dioxide can cause precipitation of organic materials from crude oils; ${ }^{3,16-17}$ several instances of problems in field operations of $\mathrm{CO}_{2}$ miscible floods have also been reported. ${ }^{18}$ Laboratory studies ${ }^{3}$ have indicated that the extent of asphaltene deposition increases with pressure up to a maximum at the minimum miscibility pressure. These studies indicate that organic deposition in miscible $\mathrm{CO}_{2}$ flooding is most likely to occur near the transition zone. Results of phase behavior studies for a Brookhaven crude oil ${ }^{3}$ indicate that a liquid-liquid-solid region occurs within the twophase region. Organic deposition induced by $\mathrm{CO}_{2}$ occurs at concentrations of greater than $70 \mathrm{~mol} \%$ and pressures greater than $1,100 \mathrm{psi}$. The low pH that occurs when $\mathrm{CO}_{2}$ contacts brine at high pressure also is believed to promote flocculation of asphaltic material.

Organic deposition in production tubing and surface equipment can reduce the productivity of wells and necessitate costly treatments to remove the deposits. Asphaltenes that are flocculated can adsorb on rock surfaces. Clay minerals in reservoir rocks can strongly adsorb asphaltic compounds of crude oils. ${ }^{19}$ Adsorption of asphaltic material on reservoir rock has been shown to alter wettability toward a less water-wet or more oil-wet condition. Alteration of rock wettability toward a more oil-wet state may help to improve displacement efficiency in $\mathrm{CO}_{2}$ miscible flooding and reduce residual oil saturation. Flocculation 
of asphaltic material may increase sweep efficiency by lowering the mobility of the injected gas and reduce

gas injectivity. ${ }^{3}$ Recently, the effect of asphaltene deposition on rock relative permeability has drawn attention. Because of experimental difficulty, this probiem has not been thoroughly investigated.

A variety of methods have been used to mitigate the deleterious effects of organic deposition. Most of these methods are remedial and have focused on removing organic deposits rather than preventing them. Mechanical methods (pigging or cutting) have been used to remove organic deposits from producing wells. The mechanical removal of deposited asphaltenes can be a time-consuming exercise and fraught with practical problems. Chemical treatment is an alternate method. Commercial chemicals designed to dissolve deposited asphaltenes are marketed by chemical service companies. These are usually blends of aromatic solvents with additives. Circulation of solvents or hot oil has been used with varying degrees of success. In Hassi Messaoud field, ${ }^{8}$ alteration in operating conditions achieved a satisfactory solution to a serious asphaltene plugging problem. Removal of chokes in producing wells and reduction in wellhead pressures mitigated the plugging problem. By adjusting operating conditions to increase the depth at which the bubble point was reached, the asphaltene deposit that formed did not restrict flow sufficiently to require frequent solvent treatments. In Ventura Avenue (CA) field, ${ }^{6}$ production problems caused by asphaltene deposition were observed to occur at pressures near and slightly above the bubble point.

Further information about the mechanisms of depesition and composition effect on the solubility of deposits in oil is needed to understand how to remediate or avoid the problem. The objective of this research was to study the relationship between organic deposition and oil composition and to develop a predictive model for the estimation of organic deposition under miscible conditions. The research was divided into two parts: asphaltene precipitation and wax formation. Results are discussed in the following sections.

\section{PART I: ASPHALTENE PRECIPITATION}

\section{Characterlstics of Asphaltene}

The asphaltene fraction of crude oils is a brown-to-black, amorphous, powdery, solid material insoluble in light normal alkanes and ether but soluble for the most part in organic solvents such as benzene, toluene, and pyridine. Although many projects have been conducted to study the composition and structure of asphaltenes, ${ }^{9-10,20-24}$ the actual structure of asphaltene in solution is still unknown. Yen et al. ${ }^{9}$ proposed a structural model made of stacks of a few aromatic sheets surrounded by some aliphatic chains. However, the model was developed based on X-Ray diffraction data collecied on solid phase and may be different from their structure in solution. In the liquid phase, there is probably a colloidal polydispersion in both size and shape. ${ }^{10,25}$ in recent studies by Ravey et al., ${ }^{10}$ they found that the 
asphaltenes in solution appeared to be essentially bidimensional 'aggregates' or collections of aromatic units. They also concluded that the "primary' particles must be considered as a whole set of polydisperse sheet-like particles, with diameters in the typical range of 2 to $10 \mathrm{~nm}$, and for which the average molecular weights are about 30,000 . With good solvents, the (reversible) association between large and small primary particles may be more or less pronounced, but always leads to very flat aggregates. With flocculating solvents, however, associations between large primary particles are more likely, leading to the formation of very open three-dimensional aggregates, for which the simplest model of disc-like particles is no longer valid, as was shown by neutron scattering measurements. Light scattering, small-angle X-Ray scattering (SAXS), and small-angle neutron scattering (SANS) are often-used techniques for the characterization of colloidal systems. ${ }^{10}$ Earlier studies, based on the techniques of ultracentrifugation 26 and electron microscopy, 22 indicated a particulate nature for asphaltenes with sizes of 20 to $40 \AA$ diameter. The dependence of aggregation size on temperature, concentration, and solvent is not addressed by earlier models. Overfield et al. ${ }^{27}$ reported that aggregation size of vacuum resid asphaltene is temperature dependent. Ravey et al. ${ }^{10}$ reported that the asphaltene particle size is twice as large in benzene as in pyridine; hence, asphaltenes are not colloids of fixed size. The aggregation creates a good deal of uncertainty as to the true molecular size or weight of asphaltenes. ${ }^{27}$ The variations of the apparent molecular weight with the solvent have been known for many years. The mean molecular weights derived from neutron data vary from one sample to another, but are generally $>20,000$. This value is not in agreement with those obtained from colligative methods such as tonorietry, osmometry, or cryoscopy, which give values in the range of 2,000 to $10,000.10$ These evidences suggest the existence of a large amount of polydispersity. Gei permeation chromatography (GPC) has been used to determine molecularsize distributions of asphaltenes. In considering the above results, the important problem remains as to whether one is dealing with primary particles or with aggregates.

Asphaltenes are considered particles colloidally suspended in crude oil by the peptization of "adsorbed" resins. This process is the basis of the thermodynamic-colloidal model proposed earlier by Leontaritis and Mansoori. ${ }^{28}$ Experiments demonstrate that once the adsorption equilibrium of the resins between solid (asphaltene) and liquid phases is disturbed by adding paraffinic solvents, the asphaltene particles flocculate irreversibly. In general, colloidal systems are thermodynamically unstable because of the large surface area of the dispersed phase and the dispersion medium. Asphaltene particles are stabilized in crude oil by the repulsion of the adsorbed resin molecules. The Electric Double-Layer theory and the Steric Stabilization theory have been used to describe the stability of asphaltene particles in crude oil and to predict the onset of asphaltene precipitation. ${ }^{15}$ Asphaltenes and resins are very important components of crude oil because they play a crucial role in the asphaltene deposition problem. Dickie and Yen 22 considered that petroleum resins provide a transition between the polar (asphaltene) and the relatively nonpolar (oil) fractions in petroleum, and thus, preventing the assembly of polar aggregates that 
would be nondispersible in oil. Koots and Speight ${ }^{12}$ found that there were notable decreases in the H/C ratios of asphaltenes relative to the $\mathrm{H} / \mathrm{C}$ ratios of resins. This presumably indicates that aromatization is more advanced in asphaltenes than in resins. They also assumed that resins associate with asphaltenes in the manner of an electron donor-acceptor system and that there could well be several points of structural similarity between asphaltene and resins. Characterization of the physical and chemical properties of resins and asphaltenes in crude oil is needed for mathematical modeling and predicting the phenomenon of asphaltene flocculation.

\section{Experiments}

Experiments conducted in this work were focused on the property of solubility of asphaltenes in solvents and oils. A sample oil obtained from Seminole-San Andres (TX) field was used in this work. The sample oil is a dead oil taken from surface equipment. Therefore, the oil cannot represent the original reservoir crude. A bottom hole pressure sample of the oil is needed to determine the actual asphaltene content. The composition of the oil (table 2) was determined by simulated distillation GC analysis. Results of asphaltene precipitation by titration with n-paraffins $\left(n-C_{5}, n-C_{7}, n-C_{10}\right.$, and $\left.n-C_{12}\right)$ are given in table 3 . As shown in figure 1, asphaltenes precipitated from crude oil with $n$-paraffins decrease as the carbon number of $n$-paraffins increases. Colors of the precipitated asphaltenes are slightly different. A sequential precipitation procedure using $n-C_{5}$ followed by $n-C_{7}$ increases the precipitate over that obtained by $n-C_{7}$ only, and the same result is found with $n-C_{10}$. The quantitative difference is shown in figure 2 . Zhang et al. 20 found that the molecular weight (MW) of the $n-C_{7}$ soluble fraction of the $C_{5}$-precipitates is lower than that of the original $n-C_{5}$ insoluble fraction, and the $M W$ of the $n-C_{7}$ insoluble fraction of the $C_{5}$-precipitates is higher than that of the $n-C_{5}$ insoluble fraction. Also, the atomic $\mathrm{H} / \mathrm{C}$ ratios decrease, and the sulfur contents of the precipitates tend to increase with the increase of carbon number of n-paraffins.

Experiments using the GPC technique to determine and compare the molecular weight distribution for the precipitates obtained by different solvents and methods have been conducted. Results are not conclusive because the base line of the GPC elusion curve shift is too large. Other research has reported the difference in the molecular distribution for the asphaltenes precipitated by different $n$-paraffins. ${ }^{29}$ Solubility reversibility for asphaltene and oil has been tested by remixing asphaltene precipitate with original oil (asphaltene-free). Before mixing with the asphaltene, the oil was restored to its original composition (except asphaltene) by vaporizing the added $n$-pentane. Results showed that approximately $23 \%$ of the asphaltene redissolved in the oil. Other tests to study the effects of aromatic solvents on the reversibility of the asphaltene precipitation-dissolution process have been performed. The first experiment was designed to study the effect of aromatic solvent on the reversibility of asphaltene dissolution in oil. The test is similar to the above-mentioned test. But, in the test, the asphaltene was 
TABLE 2. - Composition of sample oil (dead oil)

\begin{tabular}{|c|c|c|c|}
\hline Carbon Ne & Molecular wt & Weiaht \% & Mol \% \\
\hline $\mathrm{C} 5$ & 72.2 & 1.619 & 3.21 \\
\hline C6 & 86.2 & 6.092 & 10.11 \\
\hline $\mathrm{C7}$ & 100.2 & 10.722 & 15.30 \\
\hline C8 & 114.2 & 13.165 & 16.49 \\
\hline $\mathrm{Cg}$ & 128.2 & 17.975 & 20.05 \\
\hline C10 & 142.3 & 2.691 & 2.70 \\
\hline$C 11$ & 156.3 & 8.022 & 7.34 \\
\hline$C 12$ & 170.3 & 5.094 & 4.28 \\
\hline$C 13$ & 184.4 & 4.826 & 3.74 \\
\hline C14 & 198.4 & 4.763 & 3.43 \\
\hline$C 15$ & 212.4 & 3.972 & 2.67 \\
\hline C16 & 226.4 & 2.931 & 1.85 \\
\hline$C 17$ & 240.5 & 3.264 & 1.94 \\
\hline C18 & 254.5 & 2.745 & 1.54 \\
\hline C19 & 268.5 & 1.767 & 0.94 \\
\hline $\mathrm{C} 20$ & 282.5 & 1.832 & 0.93 \\
\hline $\mathrm{C} 21$ & 296.6 & 0.980 & 0.47 \\
\hline $\mathrm{C} 22$ & 310.6 & 1.313 & 0.60 \\
\hline $\mathrm{C} 23$ & 324.6 & 0.474 & 0.21 \\
\hline $\mathrm{C} 24$ & 338.6 & 0.597 & 0.25 \\
\hline $\mathrm{C} 25$ & 352.7 & 0.764 & 0.31 \\
\hline $\mathrm{C} 26$ & 366.7 & 1.036 & 0.40 \\
\hline $\mathrm{C} 27$ & 380.7 & 1.639 & 0.62 \\
\hline $\mathrm{C} 28$ & 394.7 & 0.958 & 0.35 \\
\hline C29 & 408.7 & 0.451 & 0.16 \\
\hline $\mathrm{C} 30$ & 422.7 & 0.183 & 0.06 \\
\hline C31 & 436.7 & 0.050 & 0.02 \\
\hline $\mathrm{C} 32$ & 450.8 & 0.053 & 0.02 \\
\hline C33 & 464.8 & 0.022 & 0.01 \\
\hline Totals & & 100.0 & 100.0 \\
\hline
\end{tabular}


TABLE 3. - Results of hydrocarbon titration

\begin{tabular}{|c|c|c|c|c|c|}
\hline $\begin{array}{l}\text { Hydrocarbon } \\
\text { solvent }\end{array}$ & $\begin{array}{l}\text { Wt of } \\
\text { oil, } g\end{array}$ & $\begin{array}{l}\text { Volume of } \\
\text { solvent, } \mathrm{mL}\end{array}$ & $\begin{array}{l}\text { Solvent/ } \\
\text { oil ratio, } \\
\text { mL/g }\end{array}$ & $\begin{array}{l}\text { Wi, g of } \\
\text { precipitate }\end{array}$ & $\begin{array}{l}\text { Wt \% of } \\
\text { precipitate }\end{array}$ \\
\hline$n-C 5$ & $\begin{array}{r}19.04 \\
10.63 \\
9.95 \\
9.87 \\
9.91\end{array}$ & $\begin{array}{l}19.0 \\
21.3 \\
29.9 \\
49.3 \\
99.1\end{array}$ & $\begin{array}{r}1: 1 \\
2: 1 \\
3: 1 \\
5: 1 \\
10: 1\end{array}$ & $\begin{array}{l}0.07 \\
0.07 \\
0.07 \\
0.08 \\
0.10\end{array}$ & $\begin{array}{l}0.37 \\
0.66 \\
0.70 \\
0.81 \\
1.01\end{array}$ \\
\hline $\mathrm{n}-\mathrm{C} 7$ & $\begin{array}{r}10.63 \\
9.59 \\
11.32 \\
11.74 \\
10.59 \\
9.42\end{array}$ & $\begin{array}{r}10.6 \\
19.2 \\
34.0 \\
58.7 \\
105.6 \\
188.4\end{array}$ & $\begin{array}{r}1: 1 \\
2: 1 \\
3: 1 \\
5: 1 \\
10: 1 \\
20: 1\end{array}$ & $\begin{array}{l}0.02 \\
0.03 \\
0.06 \\
0.05 \\
0.04 \\
0.05\end{array}$ & $\begin{array}{l}0.19 \\
0.31 \\
0.53 \\
0.51 \\
0.47 \\
0.53\end{array}$ \\
\hline $\mathrm{n}-\mathrm{C} 10$ & $\begin{array}{r}10.17 \\
11.01 \\
10.37 \\
8.95 \\
8.84\end{array}$ & $\begin{array}{l}10.2 \\
22.2 \\
31.1 \\
44.8 \\
88.4\end{array}$ & $\begin{array}{r}1: 1 \\
2: 1 \\
3: 1 \\
5: 1 \\
10: 1\end{array}$ & $\begin{array}{l}0.01 \\
0.02 \\
0.02 \\
0.02 \\
0.02\end{array}$ & $\begin{array}{l}0.10 \\
0.18 \\
0.19 \\
0.22 \\
0.23\end{array}$ \\
\hline $\mathrm{n}-\mathrm{C} 12$ & $\begin{array}{l}10.5 \\
10.77 \\
10.68 \\
11.39 \\
9.78\end{array}$ & $\begin{array}{l}10.5 \\
21.5 \\
32.0 \\
57.0 \\
97.8\end{array}$ & $\begin{array}{r}1: 1 \\
2: 1 \\
3: 1 \\
5: 1 \\
10: 1\end{array}$ & $\begin{array}{l}0.01 \\
0.01 \\
0.01 \\
0.02 \\
0.02\end{array}$ & $\begin{array}{l}0.10 \\
0.10 \\
0.14 \\
0.17 \\
0.16\end{array}$ \\
\hline
\end{tabular}

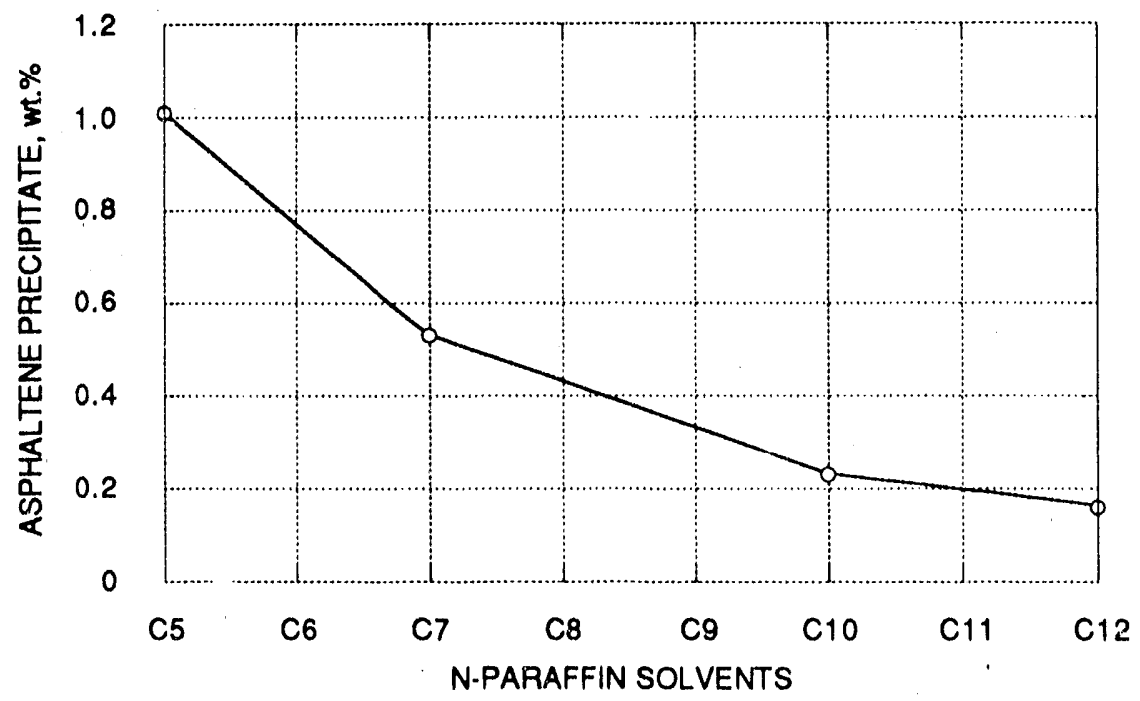

FIGURE 1. - Amount of asphaltene precipitated by $n$-paraftin titration. 


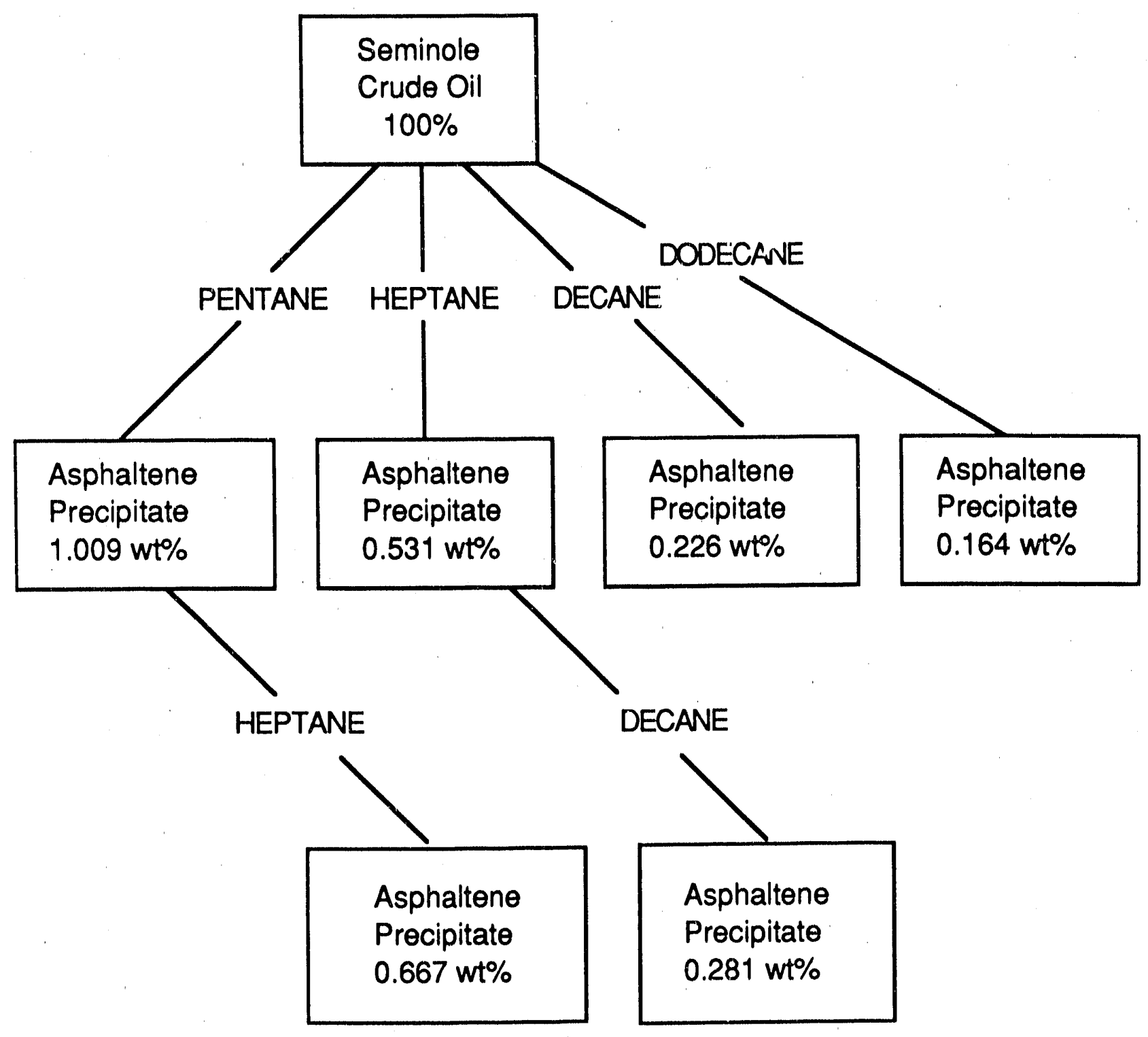

FIGIJRE 2. - Precipitation of asphaltenes using different n-alkanes 
dissolved in toluene ( $4: 1$ by weight) and then mixed with the oil. The toluene was then vaporized to recover the original oil composition. A solid asphaltic fllm was left on the filter. Approximately $56 w t \%$ of the asphaltene was dissolved in the oil. The second experiment was designed to compare asphaltene precipitation by $n$-pentane titration for two samples of the same oil. Toluene ( $22 \mathrm{vol} \%$ ) was intentionally added to one sample before pentane titration. The amount of asphaltene precipitated by $n$-pentane for these two sample oils was the same. This shows that aromatic content does not affect asphaliene precipitation. These tests also show that the asphaltene dissolution-precipitation process is not thermodynamically reversible.

Asphaltene solubility in oil is susceptible to the minor amounts of dissolved hydrocarbon and other gases in the oil. ${ }^{12}$ Hen. $e$ in gas displacement where oil and gas co-exist, solubility of the gas in the oil will presumably reduce the capacity of the oil to contain the asphaltenes and perhaps the resins also. In $\mathrm{CO}_{2}$ floods, the injected $\mathrm{CO}_{2}$ gas will not only dissolve into the reservoir oil but also extract some hydrocarbons from crude oil. Asphaltene deposition is a very common problem associated with $\mathrm{CO}_{2}$ floods. An experimental method was designed to measure the degree of solid precipitation induced by $\mathrm{CO}_{2}$ in a simulated miscible process at reservcir conditions. Figure 3 shows the experimental apparatus. The test oil was mixed with $\mathrm{CO}_{2}$ in a variable-volume PVT cell, and the oil was circulated through filters $(0.5 \mu)$ to screen the precipitates. The system was tested under a reservoir temperature of $115^{\circ} \mathrm{F}$ and at pressures varying from 1,400 to $2,500 \mathrm{psig}$. No solid precipitate was trapped in the filter. However, accumulation of asphaltenes was found in the oil retained inside the circulation pump. The test oil which contains only about $1 \%$ of asphaltene may not have been suitable for this test. Another sample oil of $35^{\circ} \mathrm{API}$ gravity was selected for the second test. The oil which was obtained from New Lon(jon (AR) oil field has about 4.57 $w t \%$ asphaltene content (by pentane titration). Experiments were conducted at $115^{\circ} \mathrm{F}$ and pressures at 1,200 and 1,500 psig. At 1,200 psig, no deposit was found on the filter during oil circulation. However, after shutdown of circulation overnight, a small amount of an asphaltic mdterial was found on the filter. The density and the asphaltene content of the oil released from the PVT cell showed a slight decrease. The density dropped from 0.8435 to $0.8072 \mathrm{~g} / \mathrm{cm}^{3}$, and asphaltene content dropped from 4.57 to $4.04 \mathrm{wt} \%$. At 1,500 psig, asphaltene deposits could be seen on the sight-glass of the PVT cell. The asphaltene content of the oil in the cell after being mixed with $\mathrm{CO}_{2}$ dropped from 4.57 to $2.04 \mathrm{Wt} \%$, and the average density dropped from 0.8435 to $0.7019 \mathrm{~g} / \mathrm{cm}^{3}$ at room temperature. The asphaltene content of the oil removed from the apparatus was $2.449 \mathrm{wt} \%$. After toluene flashing, the asphaltene content of the remaining oil trapped in the pump was determined, and about $2.057 \mathrm{wt} \%$ of asphaltene was recovernd. Evidently asphaltene had been deposited inside the apparatus after the oil was mixed with $\mathrm{CO}_{2}$. These tests also revealed some shortcomings of the apparatus design. First, the circulation pump had too large 


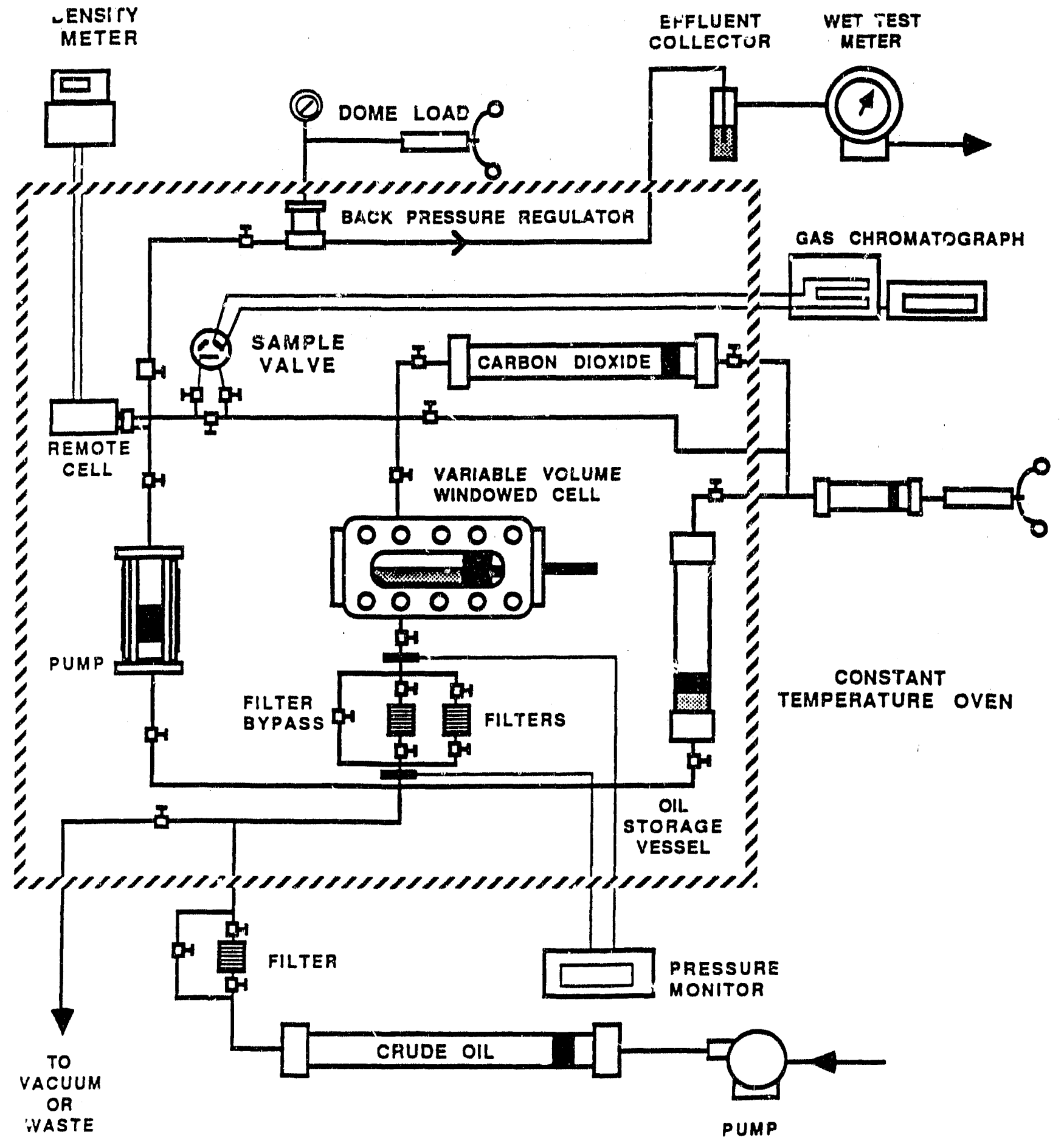

FIGURE 3. - Experimental apparatus for studying organic deposition from crude oils. 
an internal volume which retained most of the test oil inside the pump instead of in the cell. Second, the asphaltene precipitate may deposit anywhere inside the apparatus, which may not be collected on the filter. Hence quantitative measurements for the asphaltene precipitation using this apparatus is very difficult. It took a lot of effort to clean out the deposited asphaltene from the PVT cell.

\section{Modellng Asphaltene Precipltation In OII Reservolrs}

In this section a thermodynamic model to predict the magnitude of asphaltene precipitation upon changes in pressure, temperature, or compo: ".on is presented. A combination of veporiliquid equilibrium (VLE) and polymer solution theory is used to identify the conditions which may induce precipitation.

In this work, asphaltenes are defined as those components of crude oil whose molecular weight is 500 or larger. The large bulky asphaltene molecules are assumed to behave as polymer molecules. The remaining components in the crude oil are much smaller and viewed as a solvent phase in which asphaltenes are dissolved or suspended. Reported asphaltene precipitation modeling studies ${ }^{11,30}$ used this approach.

Naturally occurring reservoir crudes are ill-defined mixtures because they contain many hundreds of somponents of heptanes and heavier compounds $\left(C_{7+}\right)$. It is not possible to isolate all of the $\mathrm{C}_{7+}$ components or to assign accurate physical properties to each of them. Since our definition of asphaltene is based on molecular weight and because the computational limitation restricts the number of components that can be used to describe reservoir fluids with an equation of state (EOS) to about 15 , it is important that the $\mathrm{C}_{7+}$ fraction be accurately characterized. In this work, the $\mathrm{C}_{7}+$ fraction is characterized using the continuous thermodynamic approach. 31,32

The vapor liquid equilibrium of the characterized reservoir fluid is then modeled to obtain the composition and fluid properties of the liquid phase. The liquid phase is assumed to consist of an oil-rich phase: which acts as the solvent and an asphaltene-rich phase which behaves as the polymer. Using the liquid-liquid polymer solution theory, the volume fraction of asphaltenes soluble in the oil phase is calculated. It is assumed that the asphaltene precipitation does not alter the VLE.

In the sollowing sections the thermodynamic model for prediction of asphaltene precipitation is detailed. In section 1 , the $C_{7}+$ characterization technique based on continuous thermodynamics is presented. Continuous thermodynamics is a procedure wherein the composition of a multi-component mixture is represented through a continuous distribution function of some characterizing property such as

molecular weight. Procedures for determining the mole fractions, mulecular weight, critical properties, and acentric factor of $\mathrm{C}_{7}+$ pseudocomponents are also detailed in the section. In section 2, the VL.E model based on the Peng-Robinson $\mathrm{EOS}^{33}$ is presented. Section 3 is concerned with asphaltene precipitation 
modeling. A modified Flory-Huggiris polymer solution theory 47 is used to calculate the volume fraction of asphaltenes soluble in crude oil at a given pressure and temperature. In section 4, examples are presented for the effect of pressure, temperature, and composition on asphaltene solubility.

\section{1. $\mathrm{C}_{7 \pm}$ Characterlzation}

\subsection{Background}

Naturally occurring hydrocarbon mixtures such as oils contain numerous components. Proper description of the oil is a necessary prerequisite for accurate phase behavior modeling. The accuracy of the PVT (pressure-volume-temperature) description can be improved by using a larger number of components. However, computational time considerations and memory requirements limit the number of components that can used to represent the $C_{7}+$ fraction. Consequently, several $C_{7}+$ fraction characterization techniques have been proposed. ${ }^{34-40}$ These techniques can be broadly classified into two groups: the pseudocomponent method and the continuous thermodynamic method. The pseudocomponent-technique treated the undefined portion of the mixture either as a single pseudocomponent or as several conveniently grouped subfractiors. ${ }^{34-37}$ Since the lumping schemes involved in the pseudoization procedures are based on arbitrary rules, they are not rigorous, and their universal applicability is open to question. In the continuous therm dynamic method, a statistical distribution function $F(I)$ is used to describe the composition of the multicomponent mixture. ${ }^{38.40}$ The index $l$ is the continuous distribution variable and usually chosen to be a property such as boiling point, carbon number, or molecular weight. Early work on the continuous thermodynamic method was done by Colterman et al. ${ }^{38}$ who presented procedures for calculating phase equilibria using continuous thermodynamics. They used gamma distribution to characterize the heavy fractions. Bahrens and Sandle ${ }^{39}$ used an exponential distribution, which is a special case of gamma distribution, to describe the $\mathrm{C}_{7}+$ fraction over the desired domain. They then used Gaussian quadrature to calculate the mole fractions and molecular weights of pseudo components.

In this work, Whitson's ${ }^{40}$ modified Behrens-Sandler method was used to discretize a continuous $\mathrm{C}_{7}+$ fraction molar distribution. The pseudocomponent mole fractions and molecular weights were determined using Gaussian quadrature.

\subsection{Molar Distributlon Model}

Since a large number of oils exhibit a gamma distribution, a three-parameter gamma distribution function is used to describe the $C_{7}+$ fraction. The distribution function used in this work ${ }^{41}$ is

$$
P(M)=\frac{(M-\eta)^{\sigma-1} \exp [-(M-\eta) / \Theta]}{\Theta^{\sigma} \Gamma(\sigma)}
$$


where

$$
\begin{array}{ll}
P(M) & =\text { probability density function } \\
M & =\text { molecular weight } \\
\eta & =\text { minimum molecular weight with non zero probability of occurrence } \\
\sigma & =\text { a distribution parameter that defines the form of the distribution } \\
\theta & =\text { a distribution parameter, expressed in terms of } \alpha, \eta \text { and average } C_{7+} \text { iraction } \\
& \text { molecular weight } \\
& =\left(M 7^{+} \cdot \eta\right) / \sigma \\
\Gamma(\sigma) & =\text { gamma distribution functior }
\end{array}
$$

Also, by definition

$$
\int_{\eta}^{\infty} P(M) d M=1
$$

$\eta, \sigma$, and $M 7+$ are read as input.

\subsection{Gaussian Quadrature Method}

Gaussian quadrature is a procedure for iniegrating a function such as equation 1.3. The function is integrated by summing a finite number of weighted function evaluations at specified values of integration variables calied quadrature points. As shown by Behrens and Sandler, ${ }^{39}$ the composition distribution of $\mathrm{C}_{7+}$ fraction can be described by a collection of quadrature points, rather than by a continuous distribution function. Each quadrature point then defines the location of a pseudocomponent along the molecular we ght axis, and the weighting factor is then used to calculate the mole fraction of the pseudocomponent.

Thus, the quadrature method is analogous to the well known pseudocomponent procedure. However, unlike the pseudoccmponent method, in the quadrature method the quadrature points and weighting factors are not arbitrarily chosen, but are determined from a class of orthogonal polynomials so as to yield the best approximation of the continuous distribution. By choosing a large number of quadrature points, the distribution function can be more closely approximated. However, this results in pseudocomponents whose molecular weight is too large. It is impossible to estimate their properties. Hence, in this work, an upper limit on the molecular weights are set and the required number of quadrature points is specified accordingly. 
The quadrature procedure for generating effective mole fractions for quadrature point species is now described. In equation 1.3, the limits of the integral vary between $\eta$ and infinity. To apply the quadrature method, this integral must be transformed so as to cover the range of zero to infinity.

Substituting the expression for $P(M)$ in equation 1.3, we have

$$
\int_{\eta}^{\infty} \frac{(M-\eta)^{\sigma-1} \exp [-(M-\eta) / \theta]}{\Theta^{\sigma} \Gamma(\sigma)} d M=1
$$

Let

$$
x=\frac{M-\eta}{\Theta}
$$

Then $\quad d M=\Theta d x$

and $X=0$ for $M=\eta$

Equation 1.4 is then transformed to

$$
\int_{0}^{\infty} \frac{(x)^{\sigma-1} \exp (-x)}{\Gamma(\sigma)} d x=1
$$

When the continuous fraction follows a gamma distribution, the Chebyshev-Laguerre quadrature formula is suitable for approximating the integral given ty equation 1.7. The quadrature formula is given by

$$
\int_{0}^{\infty} e^{-x} f(x) d X=\sum_{i=1}^{N} w_{i} f\left(x_{i}\right)
$$

In equation 1.8, $X_{i}$ is the quadrature point, and $W_{i}$ is the corresponding weighting factor. Details of the formula have teen discussed by Stroud and Secrest ${ }^{41}$ who also tabulated the quadrature points and the corresponding weighting factors. 
Comparing equation 1.7 and 1.8 , we have

$$
f(x)=\frac{x^{\sigma-1}}{\Gamma(\sigma)}
$$

The mole fraction at each quadrature point is defined by

$$
z_{i}=W_{i} f\left(x_{i}\right)
$$

The corresponding molecular weight, $M_{i}$ is given by

$$
M_{i}=\eta+\left(\Theta X_{i}\right)
$$

\subsection{Calculation Procedure}

The step-by-step procedure for discretizing a continuous $\mathrm{C}_{7}+$ fraction molar distribution function using the quadrature technique is discussed.

(1) Specify $\sigma, \eta, C_{7}+$ molecular weight, number of quadrature points $N$, and the molecular weight of the heaviest pseudocomponent; that is, the molecular weight of the pseudocomponent corresponding to the last quadrature point.

(2) Obtain the weighting factor $W_{1}$ and the corresponding quadrature values $X_{i}$ for the Laguerre quadratures. $X_{i}$ and $W_{i}$ are tabulated for various values of $N$ by Stroud and Secrest, ${ }^{41}$ page 254 , or by Abramowitz and Stegun, 42 page 923.

(3) Compute $\Theta$

$$
\Theta=\frac{M_{N}-\eta}{X_{N}}
$$

where $M_{N}$ is the molecular weight of the heaviest pseudocomponent, and $X_{N}$ is the last quadratu, point.

(4) Compute the mole fraction $z_{i}$ at each quadrature point using equation 1.10 and normalize it . The true mole fraction $z_{i}$ of this quadrature point is $\mathrm{z}_{\mathrm{C} 7}+\mathrm{z}_{i}$ where $\mathrm{z}_{\mathrm{C} 7+}$ is the mole fraction of the $\mathrm{C}_{7+}$ fraction in the feed.

(5) Calculate the molecular weight of the each pseudocomponent from equation 1.11. 


\section{$1.5 C_{7+}$ Pseudocomponent Property Estlmation}

Critical properties and acentric factors of the pseudocomponents are needed in the EOS phase behavior calculation. Numerous correlations have appeared in the literature for generating critical properties from other measurable properties such as boiling point ( $\left.T_{b}\right)$ or specific gravity (SG). In this work, the critical property correlation proposed by $\mathrm{Twu}^{43}$ was used. The correlation used the molecular weight as the primary variable.

The Twu meihod consists of two parts. The first part is called the reference part where the critical properties were correlated as a function of normal boiling point. The normal boiling point was calculated from the molecular weight. The second part called the perturbation part is the correction term between the real system and the reference system. The perturbation part was correlated as a function of normal boiling point $\left(T_{b}\right)$ and the specific gravity differences $(\Delta S G)$ between the real system and the reference system.

The specific gravities of the pseudocomponenis are determined using the method proposed by Whitson. ${ }^{40}$ This method assumed that all the pseudocomponents in a giveri system have a common characterization factor $v$, where $v$ is calculated from the average $C_{7}+$ specific gravity $S G+$ together with pseudocomponent mole fractions $z_{i}$ and molecular weight $M_{i}$.

Thus,

$$
V=\left[0.16637 \mathrm{SG}+\mathrm{S}_{0} /\left(27_{+} \cdot M_{7+}\right)\right]^{-0.84573}
$$

where

$$
\begin{aligned}
& z_{7+}=\text { mole fraction of } C_{7+} \text { fraction } \\
& M_{7+}=\text { molecular weight of } C_{7+} \text { fraction } \\
& z_{i} \quad=\text { mole fraction of pseudocomponent } 1 \\
& M_{i} \quad=\text { molecular weight of the pseudocomponent } i \\
& S_{0}=\sum_{i=1}^{N} z_{i} M_{i}^{0.86459}
\end{aligned}
$$

The specific gravity of the pseudocomponent is given by

$$
S G_{i}=6.0108 M_{i}^{0.13541} v^{-1.18241}
$$

The equations for estimating pseudocomponent critical properties are given in the following sections: ${ }^{43-44}$ 
(a) Normal boiling point $\left({ }^{\circ} \mathrm{R}\right)$

$$
\begin{aligned}
& \beta_{1}=\ln \left(M_{1}\right) \\
& T_{b 1}=\exp \left[5.71419+2.71579 \beta_{1}-0.286590 \beta_{1}{ }^{2}-39.8544 / \beta_{1}\right. \\
& \left.\quad-0.122488 / \beta_{1}{ }^{2}\right]-24.7522 \beta_{1}+35.3155 \beta_{1}{ }^{2}
\end{aligned}
$$

(b) Critical temperature $\left({ }^{\circ} R\right)$

$$
\begin{aligned}
T_{C_{1}}^{O}=T_{b_{1}} /\left[0.533272+0.191017 \times 10^{-3} T_{b_{1}}+0.779681 \times 10^{-7} T_{b_{1}^{2}}\right. \\
\\
\left.-0.284376 \times 10^{-10} T_{b_{1}^{3}}+0.959468 \times 10^{28} / T_{b_{1}}^{13}\right]
\end{aligned}
$$

(c) Critical volume $\left(\mathrm{ft}^{3} / \mathrm{bb}-\mathrm{mole}\right)$

$$
V_{C_{i}}^{O}=1 /\left[1-\left(0.419869-0.505839 \alpha_{i}-1.56436 \alpha_{i}^{\beta}-9481.70 \alpha_{i}^{14}\right)\right]
$$

(d) Critical pressure (psia)

$$
P_{C_{i}}^{O}=\left[3.83354+1.19629 \alpha_{i}^{1 / 2}+34.8888 \alpha_{i}+36.1952 \alpha_{i}^{2}+104.193 \alpha_{i}^{4}\right]^{2}
$$

(e) Specific gravity

$$
S_{G_{i}}{ }^{0}=0.843593-0.128624 \alpha_{i}-3.36159 \alpha_{i}^{3}-13749.5 \alpha_{i}^{12}
$$

where

$$
\alpha_{i}=1-T_{b_{i}} / T_{c_{i}}{ }^{\circ}
$$

\section{Propertles of the Real System}

(a) Critical temperature $\left({ }^{\circ} \mathrm{R}\right)$

$$
\begin{aligned}
& T_{C_{i}}=T_{C_{i}}^{0}\left[\left(1+2 f_{T}^{i}\right) /\left(1-2 f_{T}^{i}\right)\right]^{2} \\
& f_{T}^{i}=\Delta S G_{T}^{i}\left[-0.362456 / T_{b_{i}^{1 / 2}}^{1 / 2}+\left(0.0398285-0.948125 / T_{b_{i}}^{1 / 2}\right) \Delta S G_{T}^{i}\right] \\
& \Delta S G_{T}^{i}=\exp \left[5\left(S G_{i}^{0}-S G_{i}\right)\right]-1
\end{aligned}
$$


(b) Critical volume $\left(\mathrm{tt}^{3} / \mathrm{lb}-\mathrm{mole}\right)$

$$
\begin{aligned}
& V_{C_{i}}=V_{c_{j}}\left[\left(1+2 f_{v}^{i}\right) /\left(1-2 f_{v}\right)\right]^{2} \\
& f_{v}^{l}=\Delta S_{V}\left[\left(0.466590 / T_{b_{i}}^{1 / 2}\right)+\left(-0.182421+3.01721 / T_{b_{i}}^{1 / 2}\right) \Delta S G_{V}^{i}\right] \\
& \Delta S G_{v}^{l}=\exp \left[4\left(S G_{i}^{02}-S G_{i}^{2}\right)-1\right]
\end{aligned}
$$

(c) Critica' pressure (psia)

$$
\begin{aligned}
& P_{c_{i}}= P_{c_{i}}^{0}\left(T_{c_{i}} / T_{c_{i}}^{0}\right)\left(V_{c_{i}}^{o} / V_{c_{i}}\right)\left[\left(1+2 f_{p}^{l}\right) /\left(1-2 f_{p}\right)\right]^{2} \\
& f_{p}^{l}=\Delta S G_{p}^{l}\left[\left(2.53262-46.1955 / T_{b_{i}}^{1 / 2}-0.00230535 T_{b_{i}}\right)\right. \\
&\left.+\left(-11.4277+242.140 / T_{b_{i}}^{1 / 2}+0.00230535 T_{b_{i}}\right) \Delta S G_{p}^{l}\right] \\
& \Delta S G_{p}^{i}=\exp \left[0.5\left(S G_{i}^{0}-S G_{i}\right)\right]-1.0
\end{aligned}
$$

(e) Acentric factor

The acentric factor $\omega_{i}$ were estimated using Edmister's equation, 46

$$
\omega_{i}=\frac{3}{7}\left[\frac{T_{b_{i}} / T_{c_{i}}}{1.0-T_{b_{i}} / T_{c_{i}}}\right] \log \left(P_{c_{i}}\right)-1.0
$$

In equation 1.31, the unit of $P_{C \mid}$ is atmospheres.

\section{Vapor-Llauld Equllbrlum (VLE) Model}

In this work, a VLE of the reservoir fluid is modeled so that the composition and properties of the liquid phase can be obtained at the desired pressure and temperature. The criterion for the vapor and liquid phases to be in equilibrium at a specified pressure and temperature is that the fugacities of each component in both phases nust be the same; that is,

$$
f_{i}^{L}=f_{i}^{V}
$$

Where the subscript $i$ stands for the ith component.

Fugacities are absolute quantities and can be obtained from an equation of state (EOS) by means of rigorous procedure. We used the Peng-Robinson (IJR) EOS to model the VLE of the reservoir fluid because of its ability to better predict the liquid molar volume as compared to other cubic EOS such as Soave-Redlich-Kwong (SRK) EOS. 


\subsection{Peng-Robinson Equation of State}

The Peng-Robinson equation of state has the form

$$
\begin{aligned}
& P=\frac{R T}{V-b}-\frac{a}{V(V+b)+b(V-b)} \\
& a_{i}=0.457235 \frac{R^{2} T_{c_{i}^{2}}^{2}}{P_{c_{i}}} \lambda_{i} \\
& \lambda_{i}=\left[1+m_{i}\left(1-T_{r_{i}}^{1 / 2}\right)\right]^{2} \\
& m_{i}=0.37464+1.54226 \omega_{i}-0.26992 \omega^{2} \\
& b_{i}=0.077796 \frac{R T_{c_{i}}}{P_{c_{i}}}
\end{aligned}
$$

For mixtures such as the reservoir fluid, the following mixing rules are used:

$$
\begin{aligned}
& a=\sum_{i} \sum_{i} x_{i} x_{j} a_{i j} \\
& a_{i j}=\left(a_{i} a_{j}\right)^{1 / 2}\left(1-k_{i j}\right)
\end{aligned}
$$

Where $k_{i j}$ are binary interaction coefficients

$$
b=\sum x_{i} b_{i}
$$

The binary interaction parameters are calculated using a modified Chueh-Prausnitz relation 40

$$
\begin{aligned}
& k_{i j}=0.15\left\{1-\left[\frac{2\left(v_{c_{i}} v_{c_{j}}\right)^{1 / 6}}{v_{c_{i}^{1 / 3}}^{1 / 6} v_{C_{j}}^{1 / 3}}\right]^{6}\right\} \\
& f_{i}=\frac{x_{i} P}{Z \cdot B} \cdot \exp \left[\frac{b_{i}}{b}(Z-1)-\frac{A}{2 \sqrt{2} B}\left(\frac{2 \sum x_{i} a_{i j}}{a}-\frac{b_{i}}{b}\right) \times \ln \frac{Z+(\sqrt{2}+1) B}{Z-(\sqrt{2}-1) B}\right]
\end{aligned}
$$

Where

$$
A=\frac{a P}{R^{2} T^{2}}
$$




$$
\begin{aligned}
& P=\frac{b P}{R T} \\
& Z=\frac{P V}{R T}
\end{aligned}
$$

and the fugacity coefficient $\phi_{i}$ for component $i$ is given by

$$
\begin{aligned}
\ln \phi_{1}= & \ln \left(\frac{f_{i}}{x_{i} P}\right)=\frac{b_{1}}{b}(Z-1)-\ln (Z-B) \\
& -\frac{A}{2 \sqrt{B}}\left[\frac{2 \sum_{1} x_{i} a_{i j}}{a}-\frac{b_{1}}{b}\right] \ln \left[\frac{Z+(\sqrt{2}+1) B}{Z-(\sqrt{2}-1) B}\right]
\end{aligned}
$$

The VLE criterion can be written in terms of thie fugacity coefficient $\phi_{i}$ as

$$
y_{i} \phi_{1}^{V}=x_{i} \phi_{i}^{L}
$$

Where the superscripts $V$ and $L$ represent the vapor phase and liquid phase, respectively, and $y_{i}$ and $x_{i}$ are the corresponding mole fractions of the ith component.

The equilibrium ratio $K_{j}$ for a component $i$ is defined as

$$
K_{1}=\frac{y_{1}}{x_{1}}=\frac{\phi_{1}^{L}}{\phi_{1}^{V}}
$$

If $V$ is the number of moles vapor in 1 mole of feed at equilibrium with the liquid phase at a given $P$, and $T$, then a material balance for each component can be written as

$$
\begin{aligned}
& u=(1-V) x_{1}+V_{y_{1}} \quad i=1 \ldots . N \\
& \text { Where } \sum_{i=1}^{N} x_{i}=\sum_{i=1}^{N} y_{i}=\sum_{i=1}^{N} z_{i}=1.0
\end{aligned}
$$

Using equations 1.47 and 1.48 , we can obtain the following relationships:

$$
\begin{aligned}
& x_{1}=\frac{z_{1}}{1+V\left(K_{1}-1.0\right)} \\
& x_{i}=\frac{K_{1} z_{1}}{1+V\left(K_{1}-1.0\right)}
\end{aligned}
$$


Substituting equatlons 1.51 and 1.52 in 1.50 and rearranging, we have

$$
g(V)=\sum_{i=1}^{N} \frac{z_{i}\left(K_{i}-1.0\right)}{1+V\left(K_{i}-1.0\right)}=0.0
$$

In the present study, equation 1.53 is solved by Newton's iteration for $V$, and then $x$ and $y$ are solved by using equations 1.51 and 1.52. Having determined the liquid-phase composition, the molar volume of the liquid-phase $V L$ at a given $P$ and $T$ is obtained from equation 1.33.

\section{Asphaltene Preclpltatlon Model}

We now present a thermadynamic model to describe the behavior of asphaltene in reservoir crude upon changes in pressure, temperature, or composition. We used a simplified version of the Flory. Huggins polymer solution theory 46 to calculate the maximum volume fraction ( $\Phi_{A}$ ) Max of asphaltenes soluble in the crude. Hirschberg et al. ${ }^{11}$ have presented the details of the model. Next, we present the step-by-step procedure for estimating the volume fraction of asphaltene soluble in the clude. The performance of the model is dependent on the molecular weight of the asphaltenes and the difference in solubility parameters between the oil and the asphaltenes. For the purpose of this work, we considered the oli (liquid phase) to be a binary mixture of two components: asphaltene (ASP in subscripts) and solvent ( $S$ in subscripts). All of the components having a molecular weight of 500 or greater are combined and classified as asphaltene. Thus, the mole fraction of asphaltene in the liquid phase is given by

$$
x_{A S P}=\sum_{I=\left(N C-N_{A}+1\right)}^{N C} x_{i}
$$

Where $N_{A}$ is the number of pseudocomponents whose molecular weight are 500 or greater.

\subsection{Procedure}

1. Characterize the $\mathrm{C} 7+$ fraction into the desired number of pseudocomponents and determine their properties.

2. Perform a VLE calculation at the given $P$ and $T$ and determine the composition and properties of the liquid phase.

3. Calculate the molar volume $V^{L}$ of the liquid phase.

4. Calculate the heat of vaporization $\left(\Delta H_{1}\right)$ T of each component in the liquid phase at any temperature $T$. The heat of vaporization is calculated using Kistyakowsky's equation. 47

$$
\left(\Delta H_{i}\right)_{T}=\left(\Delta H_{i}\right)_{B}\left(\frac{T_{C_{i}}-T}{T_{C_{i}}-T_{B_{i}}}\right)^{0.38}
$$


$\left(\Delta H_{1}\right) T_{B}=1.014\left[T_{B_{1}}\left(8.75+4.571 \log \left(T_{B_{i}}\right)\right)\right]$

$T_{B_{1}}=$ normal bolling point of component $\mathrm{l},{ }^{\circ} \mathrm{K}$

$T_{q_{1}}=$ critical temperature of component $I_{1}{ }^{\circ} \mathrm{K}$

The unit of $\left(\Delta H_{1}\right)$ is cal/gm-mole (Btu/lb-mole)

5. Compute asphaltene and solvent mole fractions

$$
\begin{aligned}
& x_{s}=\sum_{i=1}^{N C-N A} x_{i} \\
& x_{A S P}=\sum_{i=\left(N C-N_{A}+1\right)}^{N C} x_{i}
\end{aligned}
$$

Where NC = total number of components in the liquid-phase

$$
N_{A}=\text { number of components having a molecular weight of } 500 \text { or larger }
$$

6. Compute liquid-phase component molar volumes $V_{-}^{L}$

$$
v_{i}^{L}=x_{i} V^{L}
$$

$V_{A S P}^{L}=X A S P V^{L}$

$V_{S}^{L}=V^{L}-V_{A S P}$

7. Compute the solubility parameter $\delta$ in the liquid phase

$$
\delta_{i}=\left[\frac{\left(\Delta H_{i}\right) T-R T}{V_{i}^{L}}\right]^{1 / 2}
$$

8. Compute the volume fraction $\Phi_{i}^{L}$ of component i

$$
\Phi_{i}^{L}=\frac{x_{i} v_{i}^{L}}{\sum_{i=1}^{N} x_{i} v_{i}^{L}}
$$


9. Compute the solubility parameters for solvent $\left(\delta_{S}\right)$ and asphaltene $\left(\delta_{A}\right)$

$$
\begin{aligned}
& \delta_{S}=\sum_{i=1}^{N C-N A} \Phi_{i}^{L} \delta_{i}^{L} \\
& \delta_{A}=\sum_{l=\left(N C-N_{A+1}\right)}^{N C} \Phi_{i}^{L} \delta_{i}^{L}
\end{aligned}
$$

10. Compute the solvent volume fraction $\Phi \frac{\mathrm{s}}{\mathrm{s}}$

$$
\Phi=\frac{x_{S} V^{L}}{V^{L}}
$$

11. Using the Flory-Huggins polymer solution theory, compute the maximum volume fraction $\left(\Phi_{A}\right)$ Max of asphaltenes soluble in the crude at a given pressure, temperature, and composition.

$$
\left(\Phi_{A}\right)_{M a x}=\exp \left[\left(\frac{V_{A_{S p}}^{L}-1}{V_{S}^{L}}\right) \Phi_{S}^{L} \cdot \frac{\left(\delta_{A}-\delta_{S}\right)^{2}}{R T} V_{A}^{L}\left(\Phi_{S}^{L}\right)^{2}\right]
$$

\subsection{Discussion}

A computer prograin was written to calculate the maximum volume fraction of asphaltenes soluble in the crude oil at a given condition. The developed model was tested with hypothetical crudes to study the effect of temperature and composition. For a given temperature and/or composition, VL.E calculations were performed at various pressures, and the maximum volume fraction of asphaltene soluble in the crus : oll was ralculated, and results were plotted as a function of pressure.

\section{Iemperalure Elfects}

Figure 4 compares the maximum volume percent of asphaltene soluble in the crude at two different temperatures. This plot indicates that at any pressure, the solubility of asphaltene is greater at the lower temperature. This observed increase in solubility is caused by the variation of $V_{s}^{L}$ and $\delta_{s}$ with temperature at constant pressure.

For a liquid, temperature affects both the heat of vaporization and the density. Since $V_{S}^{L}$ is roughly proportional to $T$ and $\delta_{S}$ is inversely proportional to $V_{S}^{L}$ at a given $P, \delta_{S}$ increases as the temperature decreases. This decrease in temperature decreases $\left(\delta_{A}-\delta_{B}\right)$ and increases $V_{A S P}^{L} / V_{S}^{L}$. Equation 1.67 shows that both these effects enhance the asphaltene solubility at lower temperature. This trend is in accordance with the published model studies. ${ }^{32}$ 


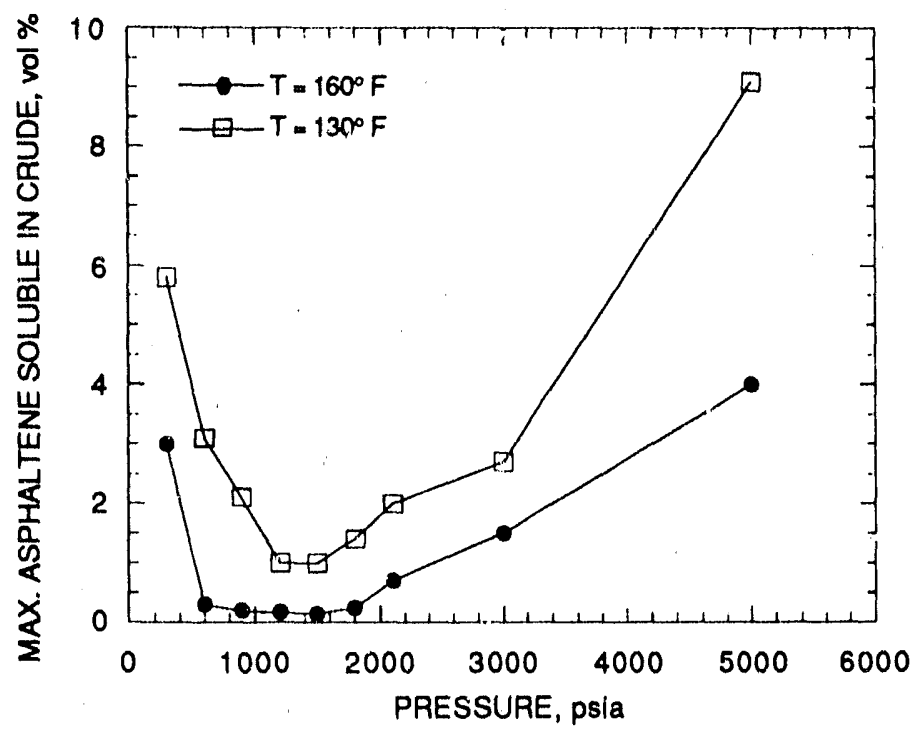

FIGURE 4. - Effect of pressure and temperature on asphaltene solubility.

\section{Composition Effects}

Figure 5 compares the maximum volume percent of asphattene soluble in crude at three different oil compositions. To study the effect of composition on asphaltene precipitation, the $\mathrm{C}_{7+}$ fraction mole fraction in the crude was varied from 0.4 to 0.7 , and the light end $\left(C_{1} \cdot C_{5}\right)$ was adjusted accordingly. This plot indicates that altering the composition of the reservoir fluid system can have significant impact on asphaltene solubility. This plot indicates that as the concentration of heavy components in the crude increases, the asphaltene solubility increases at a given pressure and temperature.

\section{Pressure Effects}

Both figures 4 and 5 indicate that altering the pressure can have a significant impact on asphaltene solubility. Below the bubble point, asphaltene solubility decreases with increase in pressure and reaches a minimum value at the bubble point. Above the bubble point, asphaltene solubility increases with pressure. As pointed out by Hirschberg et al. ${ }^{11}$ above the bubble point, there is no composition change, and the observed increase in solubility is caused by the variation in $V_{S}^{L}$ and $\delta_{S}$ with pressure. 


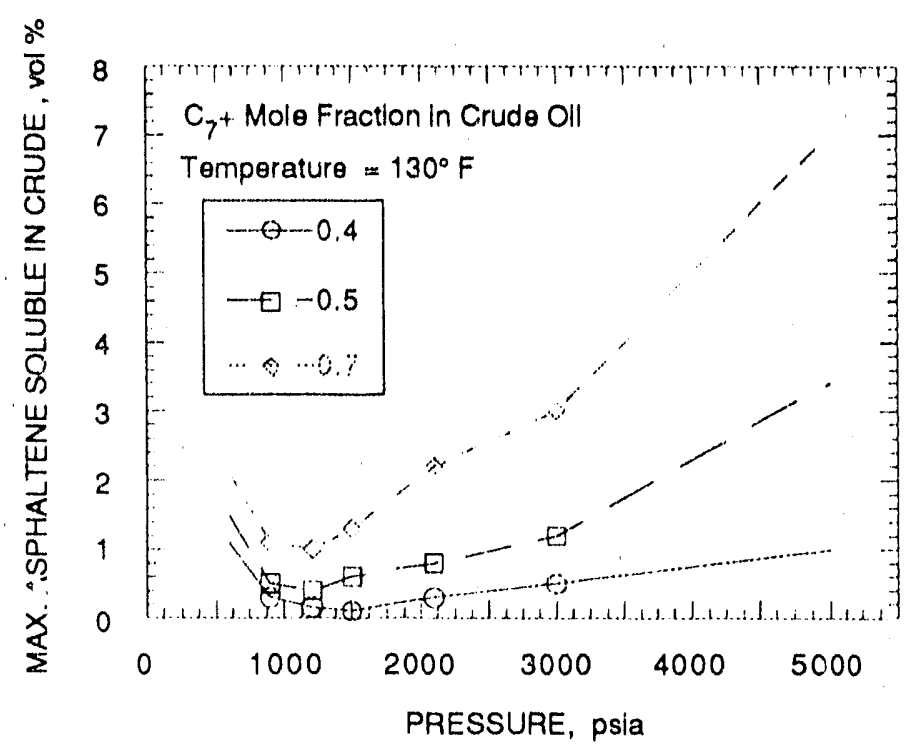

FIGURE 5. - Effect of composition on asphaltene solutility. 


\section{PART II. WAX FORMATION}

The deposited organic material scraped from the downhole tube of the producing well contains asphaltene, resin, and wax. Most crude oils contain high-molecular-weight paraffins which may solidify as a wax phase at low temperatures. Large fractions of waxy constituents were reported among the new crude oils in the Alaskan North Slope. Wax formation is due mainly to temperature drop which is different from the formation of asphaltenes. Thus, wax often accumulates at a cerlain spot inside the producing well. However, wax formation can also cause asphaltene precipitation, which was found from the collected material. Wax precipitation may cause plugging of producing wells and transfer pipes. This problem is even more serious in oil production areas such as the Alaskan North Slope and North Sea. Predicting wax formation is critical to the solution of the problem and is required for process design in petroleum refining. Thermodynamic modeling for predicting wax formation in crude oil is simpler than for predicting asphaltene precipitation. The principle for wax formation and the chemical constituents of wax are well known. Wax formation is a reversible process. As long as the temperature increases back to the original level, the wax phase will melt and dissolve into the oil. Thermodynamic phase equilibrium criteria can be applied to predict wax formation. The only problem is how to treat the wax phase. Wax formation is composed of two processes: nucleation and crystal growth.

\section{Thermodynamic models}

To apply phase equilibrium criteria, the wax phase is treated as a homogeneous solid solution (S), which is in equilibrium with a liquid solution (L). At equilibrium between a liquid phase (oil) and a solid phase (wax), the fugacities $\left(f_{i}\right)$ for component $i$ in both phases must be the same; that is,

$$
f_{i}^{L}=f_{i}^{s}
$$

and the following equation is fulfilled for component $i$ :

$$
\ln \left(\frac{a_{i}^{s}}{a_{1}}\right)=\frac{\Delta H_{i}^{f}}{R T}\left(1-T / T_{i}^{f}\right)+\frac{\Delta C_{p_{1} i}}{R}\left(T_{i}^{f} / T-1\right)-\frac{\Delta C_{p_{,} i}}{R} \ln \left(T_{i}^{f} / T\right)
$$

where, $a_{l}^{s}$ is the activity of the component in the solid phase, $a_{\uparrow}^{t}$ is the activity in the liquid-phase, $\Delta H_{i}^{\dagger}$ is the enthalpy of melting. $T_{i}^{\dagger}$ is the melting point temperature, and $R$ is the gas constant. $\Delta C_{p, i}$ is the difference between the molar heat capacities of the substance in the subcooled liquid state and in the solid state. The last two terms in equation 2.2 are close to zero and can be neglected. Equation 2.2 can be rewritten in terms of the equilibrium ratio, $K_{i}^{s L}$,

$$
K_{i}^{s L}=\frac{S_{i}}{X_{i}}=\frac{v_{i}^{t}}{v_{i}^{s}} \exp \left[\frac{\Delta H_{i}^{\dagger}}{R T}\left(1-T / T_{i}^{f}\right)\right]
$$


Where $S_{i}$ is the composition of component $i$ in the solid phase (wax), and $x_{i}$ is the composition of $i$ component in the liquid-phase (oil). $\gamma \beta$ and $\gamma f$ are the activity coefficients of component $i$ in the solid and the liquid phases, respectively.

A correlation for estimating the melting point temperature of the components was proposed by Won. 48 Won's correlation was developed based on the melting temperatures of $n$-paraffins. Since $n$ paraffin fraction decreases with increasing carbon number, and the melting temperatures for ring or branch-chain hydrocarbons are lower than those of straight chain compounds, Won's correlation was modified slightly by Hansen et al. ${ }^{49}$ as,

$$
T_{i}^{f}=402.4-0.01896 \cdot M W_{i} \cdot \frac{27109}{M W_{i}}
$$

$M W_{i}$ is the molecular weight of component $\mathrm{I}$. The enthalpy of melting is estimated using the correlation proposed by Won:48

$$
\Delta H_{i}^{q}=0.1426 \cdot M W_{1} \cdot T_{i}^{q}
$$

In equation 2.3, the activity coefficient ratios, $\gamma / / \gamma$, can be estimated by the following models:

1. Regular solution theory

Won ${ }^{48}$ used a modified regular solution theory and solubility parameters to estimate the activity coefficients of components in both phases,

$$
\begin{aligned}
& \ln \eta_{1}=\frac{V_{i}}{R T}\left(\bar{\delta}-\delta_{i}\right)^{2} \\
& \bar{\delta}=\sum \phi_{i} \delta_{i} \\
& \Phi_{i}^{L}=\frac{x_{i} V_{i}}{\sum_{i} x_{j} V_{j}} \text { and } \phi_{i}^{*}=\frac{S_{j} V_{i}}{\sum S_{j} V_{j}}
\end{aligned}
$$

where $V_{i}$ is the molar volume, $\delta_{i}$ is the solublity parameter, $\Phi_{1}$, is the volume fraction of component $i$, and $\bar{\delta}$ is the average solubility parameter of the mixturs.

The solubility parameter of component $\mathrm{i}$ in liquid solution is defined as,

$$
\delta_{i}^{L}=\left(\frac{\Delta H^{V}-R T}{V}\right)_{i}^{1 / 2}
$$


The solid solubility parameters, $\delta_{1}^{8}$, which were estimated from a modified cohesive energy of a component $i$ in solid solutions, were presented by Won 48 for hydrocarbon fractions up to $\mathrm{C}_{40}$.

In equation 2.8 , the molar volume $V_{1}$ was estimated by the following correlation: 48

$$
\begin{aligned}
& V_{i}=M W_{i} / d_{25}^{d} \\
& d_{25}^{L}=0.8155+0.6272 \times 10^{-4} \cdot M W_{1}-13.06 / M W_{i}
\end{aligned}
$$

Substitution of equation 6 into equation 3 ylelds,

$$
K_{i}^{s L}=\frac{S_{i}}{x_{i}}=\exp \left[\frac{\Delta H_{i}^{f}}{R T}\left(1-T / T_{i}^{f}\right)+\frac{V_{i}}{R T}\left((\bar{\delta}-\delta)^{2} \cdot(\bar{\delta}-\delta)_{B}^{2}\right)\right]
$$

\section{Polymer solution thery}

The liquid phase activity coefficients were modeled using a generalized polymer solution theory 50 by Hansen et al. 49 The following thermodynamic relation was used:

$$
\frac{\Delta G^{M}}{R T}=\frac{\Delta H^{M}}{R T}-\frac{\Delta S^{M}}{F}=\sum_{i} \sum_{i=} n_{i} \Phi_{j} x_{i j}+\sum_{i} n_{i} \ln \Phi_{i}
$$

and

$$
\ln a_{k}=\sum_{j \neq k} \chi_{j} \Sigma \phi_{k}-\sum_{j \neq k} \sum_{k<j}\left(\frac{\xi_{k}}{\xi_{i}}\right) \phi_{i} \phi_{j} x_{i j}+\ln \phi_{k}+1-\sum_{k \neq k}\left(\frac{\xi_{k}}{\xi_{j}}\right) \phi_{i}
$$

where $\Delta G^{M}, \Delta H^{M}$ ! and $\Delta S^{M}$ are the change of free energy, anthalpy, and entropy, respectivaly, during mixing. The volumu fraction $\Phi_{1}$ was expressed as,

$$
\Phi_{i}=\frac{\xi_{i} x_{i}}{\sum_{j} \xi_{j} x_{j}}
$$

$\xi_{i}$ is the carbon number of component $i$, and $n_{i}$ is the number of moles of component $i . x_{i j}$ is a binary interaction parameter describing the interactions between molecules $\mid$ and $\}$, and the following relation applies: 


$$
\chi_{\| 1}=\chi_{i j}\left(\frac{\xi_{j}}{\xi_{j}}\right)
$$

A group-contribution approach was used to model the interaction parameters. Each fraction was divided into paraffinic $(P)$, naphthenic $(N)$, and aromatic $(A)$ groups. Group interaction parameters are required for the following three different types of interactions:

$$
\begin{aligned}
& \text { 1. } P N-P N \\
& \text { 2. } P N-A \\
& \text { 3. A - A }
\end{aligned}
$$

Three correlations were developed for these three interaction parameters by Hansen et al. 49

The regular solution model is a simplified model with the neglection of the entropy of mixing, which is important for mixtures of large molecules different in size and structure. The results of using Won's model to predict the wax appearance point (WAP) are much too high. 49 The polymer solution model has significantly improved the accuracy of WAP prediction. However, this model requires interactioin parameters which have to be determined from empirical correlations of data regression. In this work, an approach was used to improve the regular solution model. A thermodynamic model was proposed as follows:

$$
\frac{\Delta G^{E}}{R T}=\frac{\Delta H^{E}}{R T}-\frac{\Delta S^{E}}{R}=\frac{N V_{m}}{2} \sum_{i} \sum_{j} A_{i j} \Phi_{i} \Phi_{j}+\sum_{i} n_{i} \ln \frac{\Phi_{i}}{\sum_{j} x_{j} V_{j}}
$$

where $N V m=\sum n_{i} V_{i}, A_{i j}$ are coefficients, the superscript $E$ denotes the excess property. According to thermodynamic relationship, we can obtain the activity coefficient irom equation 2.17 ,

$$
\ln \gamma=\frac{\partial}{\ln _{k}}\left(\frac{\Delta G}{R T}\right)_{T, P, n_{i \neq k}}=V_{k}\left(\bar{\delta}-\delta_{k}\right)^{2}+\ln \frac{\Phi_{k}}{x_{k}}+1-\Phi_{k}-\sum_{i \neq k}^{N} \frac{V_{k}}{V_{i}} \Phi_{i}
$$

Here we include entropy effect into the activity coefficient for liquid solution. The volume fraction $\Phi_{j}$ is defined as

$$
\Phi_{i}=\frac{x_{i} v_{i}}{\sum_{j} x_{j} v_{j}}
$$


where the molar volume $V_{1}$ is estimated by equation 2.10 , and the solubility pararneters proposed by Won 48 were used in all our calculations. This model is as simple as the regular solution model, and no empirical parameter is required.

\section{Il. Calculation Algorithm}

Vapor-liquid equilibrium calculations were conducted to obtain the liquid (oll) composition. The liquid-solid equilibrium calculation was then performed by solving the following mass balance equations with equation 2.3 simultaneously,

$$
\begin{aligned}
& F^{s L}=\Sigma S_{i}-\Sigma x_{i}=\Sigma \frac{z_{i}\left(K_{i}^{s L}-1\right)}{\left[1+\frac{S}{F}\left(K_{i}^{s L}-1\right)\right]}=0 \\
& x_{i}=z_{i} /\left[1+\frac{S}{F}\left(K_{i}^{s L}-1\right)\right] \\
& S_{i}=z_{i} K_{i}^{S L} /\left[1+\frac{S}{F}\left(K_{i}^{S L}-1\right)\right]
\end{aligned}
$$

where $z_{i}$ is the feed composition and $S / F$ is the mole fraction of solid (wax) to feed. The wax appearance point (WAP) is the temperature at which the solid fraction (S/F) approaches zero. When the temperature is above the WAP temperature, equation 2.20 will not converge with $S / F$ equal to zero. Therefore, if the solution does not converge to a finite value of $S / F$ after 100 iterations, the system is considered as a single liquid phase, that is, no wax is formed. Equations 2.20 to 2.22 and equation 2.3 are mutually dependent. An iteration method as illustrated in figure 6 was developed to solve these equations.

\section{Calculation Results}

Prediction of the WAP for a crude oil using the developed model is straightforward. The only input is oil composition, which can be the carbon number distribution determined from simulated distillation GC analysis. Many methods have been developed to characterize the $C_{7+}$ fraction of the oil mixtures. 37,44 The developed model was tested with two reported data ${ }^{49}$ and two in-house measured data. Results are shown in tables 4107 . It can be seen that the model developed in this work is more accurate than Won's model which predicts WAP too high. It also shows that the addition of entropy effect to the activity coefficient does improve the prediction accuracy. We didn't compare with the model of Hansen et al. because the model requires the PNA (paraffin, naphthene, aromatic) distributions for each of the carbon number fractions. For No.1 and No. 2 samples, the molecular weights for each carbon number fraction were reported by Hansen et al., which were a little different from the values used in our analysis for No.3 and No.4 samples. For each carbon number fraction, we used the molecular weight of the corresponding 


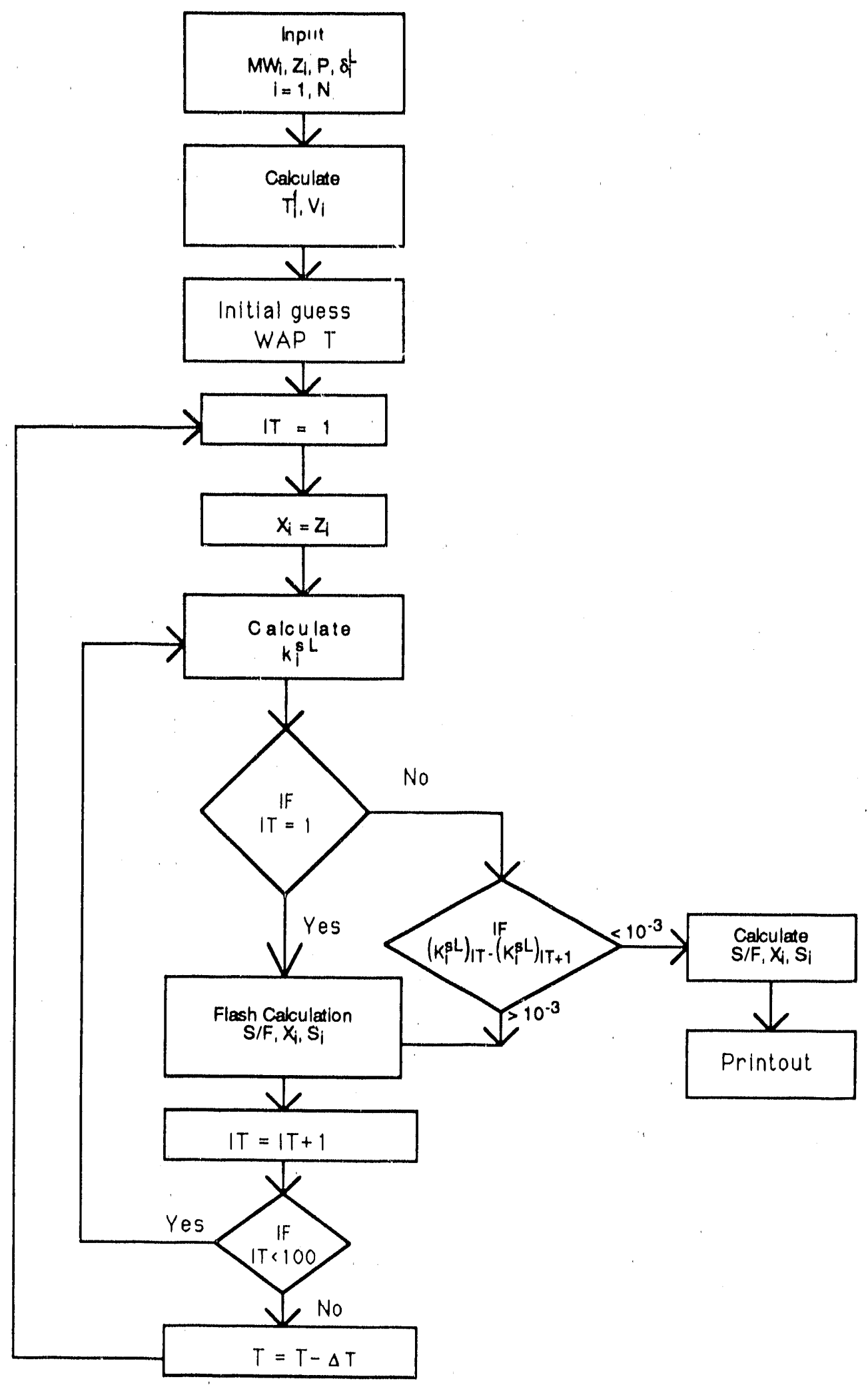

FIGURE 6. - Calculation method for wax formation. 
TABLE 4. - Sample oll No. 11

\begin{tabular}{|c|c|c|c|c|}
\hline Compenent & Molwt & Mol\% & $\delta_{\left.(\mathrm{cal} / \mathrm{cm})^{3}\right)^{1 / 2}}$ & $\begin{array}{c}V_{1}^{3} \\
\left(\mathrm{~cm}^{3} / a \text { mole }\right)\end{array}$ \\
\hline \multirow[t]{2}{*}{$\begin{array}{r}S C 4 \\
C 5 \\
C 6 \\
C 7 \\
C 8 \\
C 9 \\
C 10 \\
C 11 \\
C 12 \\
C 13 \\
C 14 \\
C 15 \\
C 16 \\
C 17 \\
C 18 \\
C 19 \\
C 20 \\
C 21 \\
C 22 \\
C 23 \\
C 24 \\
C 25 \\
C 26 \\
C 27 \\
C 28 \\
C 29 \\
C 30+\end{array}$} & $\begin{array}{r}29 \\
71 \\
82 \\
91 \\
103 \\
116 \\
132 \\
147 \\
163 \\
175 \\
190 \\
205 \\
215 \\
237 \\
251 \\
262 \\
268 \\
284 \\
299 \\
315 \\
330 \\
342 \\
352 \\
371 \\
385 \\
399 \\
518\end{array}$ & $\begin{array}{r}0.280 \\
3.057 \\
2.292 \\
6.623 \\
6.877 \\
5.578 \\
4.789 \\
3.311 \\
3.668 \\
3.031 \\
4.916 \\
4.636 \\
2.420 \\
4.432 \\
3.821 \\
3311 \\
2.649 \\
2.955 \\
2.674 \\
2.776 \\
2.522 \\
2.216 \\
2.191 \\
1.426 \\
1.808 \\
2.012 \\
13.729\end{array}$ & $\begin{array}{l}6.65 \\
7.02 \\
7.25 \\
7.41 \\
7.53 \\
7.63 \\
7.71 \\
7.78 \\
7.83 \\
7.88 \\
7.92 \\
7.96 \\
7.99 \\
8.02 \\
8.05 \\
8.07 \\
8.09 \\
8.11 \\
8.13 \\
8.15 \\
8.17 \\
8.18 \\
8.20 \\
8.21 \\
8.22 \\
8.24 \\
8.35\end{array}$ & $\begin{array}{r}79.0 \\
111.6 \\
123.9 \\
134.3 \\
148.2 \\
163.3 \\
182.1 \\
199.8 \\
218.6 \\
232.7 \\
250.4 \\
268.1 \\
279.9 \\
305.7 \\
322.1 \\
335.0 \\
342.0 \\
360.7 \\
378.2 \\
396.8 \\
414.2 \\
428.2 \\
439.7 \\
461.7 \\
477.8 \\
493.9 \\
697.1\end{array}$ \\
\hline & & 100.00 & & \\
\hline
\end{tabular}

Measured WAP: $308 \mathrm{~K}$ (@1 atm).

Predicted WAP: $327 \mathrm{~K}$ (This work) $340 \mathrm{~K}$ (Won Method)

1 From Hansen et al. (1988)

2 From Won (1986)

${ }^{3}$ Calculailed by eq. 2.10 . 
TABLE 5. - Sample oll No. $2^{1}$

\begin{tabular}{|c|c|c|c|c|}
\hline Compenent & Molwt & $\mathrm{Mol} \%$ & $\begin{array}{c}\delta^{L^{2}}+{ }^{2} \\
\left(\mathrm{cal} / \mathrm{cm}^{3}\right)^{1 / 2}\end{array}$ & $\begin{array}{c}V_{1}^{3} \\
\left(\mathrm{~cm}^{3} / \mathrm{amole}\right)\end{array}$ \\
\hline \multirow[t]{2}{*}{$\begin{array}{r}\leq \mathrm{C} 4 \\
\mathrm{C} 5 \\
\mathrm{C} 6 \\
\mathrm{C} 7 \\
\mathrm{C} 8 \\
\mathrm{C} \\
\mathrm{C} 10 \\
\mathrm{C} 11 \\
\mathrm{C} 12 \\
\mathrm{C} 13 \\
\mathrm{C} 14 \\
\mathrm{C} 15 \\
\mathrm{C} 16 \\
\mathrm{C} 17 \\
\mathrm{C} 18 \\
\mathrm{C} 19 \\
\mathrm{C} 20+\end{array}$} & $\begin{array}{r}38 \\
65 \\
81 \\
97 \\
106 \\
119 \\
134 \\
148 \\
162 \\
177 \\
188 \\
201 \\
215 \\
234 \\
250 \\
264 \\
489\end{array}$ & $\begin{array}{r}0.197 \\
13.390 \\
6.237 \\
9.548 \\
9.239 \\
7.293 \\
3.948 \\
3.704 \\
4.036 \\
3.509 \\
2.898 \\
3.228 \\
2.585 \\
2.390 \\
2.233 \\
1.972 \\
23.593 \\
\end{array}$ & $\begin{array}{l}6.65 \\
7.02 \\
7.25 \\
7.41 \\
7.53 \\
7.63 \\
7.71 \\
7.78 \\
7.83 \\
7.88 \\
7.92 \\
7.96 \\
7.99 \\
8.02 \\
8.05 \\
8.07 \\
8.34\end{array}$ & $\begin{array}{r}80.14 \\
105.07 \\
122.8 \\
141.2 \\
151.7 \\
166.8 \\
184.5 \\
200.9 \\
217.4 \\
235.1 \\
248.1 \\
263.4 \\
279.9 \\
302.2 \\
320.9 \\
337.3 \\
596.7\end{array}$ \\
\hline & & 100.0 & & \\
\hline
\end{tabular}

Measured WAP: $314 \mathrm{~K}$ (@1 atm).

Predicted WAP: $322 \mathrm{~K}$ (This work)

$334 \mathrm{~K}$ (Won Method)

1 From Hansen et al. (1988)

2 From Won (1986)

${ }^{3}$ Calculated by eq. 2.10 . 
TABLE 6. - Sample oll No. 3

\begin{tabular}{|c|c|c|c|c|}
\hline Compenent & Molwt. & Mol. \% & $\begin{array}{c}\delta^{L^{1}} \\
(\mathrm{cal} / \mathrm{cc})^{1 / 2}\end{array}$ & $\begin{array}{c}V_{1}^{2} \\
\text { (ce/a mole) }\end{array}$ \\
\hline \multirow[t]{2}{*}{$\begin{array}{l}C 12 \\
C 13 \\
C 14 \\
C 15 \\
C 16 \\
C 17 \\
C 18 \\
C 19 \\
C 20 \\
C 21 \\
C 22+\end{array}$} & $\begin{array}{l}170.3 \\
184.4 \\
198.4 \\
212.4 \\
226.4 \\
240.5 \\
254.5 \\
268.5 \\
282.5 \\
296.6 \\
310.6\end{array}$ & $\begin{array}{r}7.30 \\
8.04 \\
11.66 \\
14.30 \\
14.00 \\
15.72 \\
11.66 \\
8.70 \\
5.05 \\
2.94 \\
0.63\end{array}$ & $\begin{array}{l}7.83 \\
7.88 \\
7.92 \\
7.96 \\
7.99 \\
8.02 \\
8.05 \\
8.07 \\
8.09 \\
8.11 \\
8.13\end{array}$ & $\begin{array}{l}227.2 \\
243.8 \\
260.3 \\
276.8 \\
293.3 \\
309.8 \\
326.2 \\
342.6 \\
358.9 \\
375.4 \\
391.7\end{array}$ \\
\hline & & 100.00 & & \\
\hline
\end{tabular}

Measured WAP: 265 K (@1 atm).

Predicted WAP: $286 \mathrm{~K}$ (Thls work)

1 From Won (1986)

$297 \mathrm{~K}$ (Won Method)

2 Calculated by eq. 2.10 .

TABL.E 7. - Sample oll No. 4

\begin{tabular}{|c|c|c|c|c|}
\hline Compenent & Mol wt. & Mol. \% & $\begin{array}{c}\delta^{L^{1}} \\
(\mathrm{cal} / \mathrm{c} c)^{1 / 2}\end{array}$ & $\begin{array}{c}V_{1}^{2} \\
(\mathrm{cc} / \mathrm{a} \text { mole })\end{array}$ \\
\hline $\begin{array}{l}C 10 \\
C 11 \\
C 12 \\
C 13 \\
C 14 \\
C 15 \\
C 16 \\
C 17 \\
C 18 \\
C 19 \\
C 20 \\
C 21 \\
C 22 \\
C 23+\end{array}$ & $\begin{array}{l}142.3 \\
156.3 \\
170.4 \\
184.4 \\
198.4 \\
212.4 \\
226.4 \\
240.5 \\
254.5 \\
268.5 \\
282.5 \\
296.6 \\
310.6 \\
338.6\end{array}$ & $\begin{array}{r}6.50 \\
11.60 \\
7.9 \\
10.1 \\
11.6 \\
13.1 \\
10.4 \\
9.6 \\
8.8 \\
4.0 \\
2.2 \\
2.4 \\
1.2 \\
0.6\end{array}$ & $\begin{array}{l}7.71 \\
7.78 \\
7.83 \\
7.88 \\
7.92 \\
7.96 \\
7.99 \\
8.02 \\
8.05 \\
8.07 \\
8.09 \\
8.11 \\
8.13 \\
8.17\end{array}$ & $\begin{array}{l}194.2 \\
210.7 \\
227.3 \\
243.8 \\
260.3 \\
276.8 \\
293.3 \\
309.8 \\
326.2 \\
342.6 \\
358.9 \\
375.4 \\
391.7 \\
424.2\end{array}$ \\
\hline & & 100.00 & & \\
\hline
\end{tabular}

Measured WAP: $268 \mathrm{~K}$ (@ 1 atm).

Predicted WAP: $282 \mathrm{~K}$ (This work) $293 \mathrm{~K}$ (Won Method)

1 From Won (1986)

2 Calculated by eq. 2.10 . 
carbon number n-paraffin. The WAP temperatures for No.3 and No.4 samples were determined by visual observation, which may not be so accurate as the first two samples measured by microscope. For black oil, It is impossible to determine the WAP by the visual observation for the wax crystal formed as the temperature drop. Therefore we chose two diesel olls, which are transparent with light, in our experiments. The predicted WAP temperatures are all higher than measured values. For No. 2 and No. 4 samples, our predicted results are close to the experimental values.

The model can be used not only to estlmate WAP but also to estimate the amount of wax formed and its composition at given temperatures. An example was given in flgure 7 for the sample oll of No. 4 to show the composition distributions of wax at several temperatures below WAP. At lower temperatures, the preclpitated wax contains more low-molecular-weight paraffins. Figure 8 gives the calculated wax precipltation at different temperature levels.

The accuracy of prediction is still not satisfactory (within $20 \mathrm{~K}$ ). The model still can be improved by modifying the parameters such as the molar volume and solubility parameters, or including the interactlons among P-N-A for each pseudocomponent.

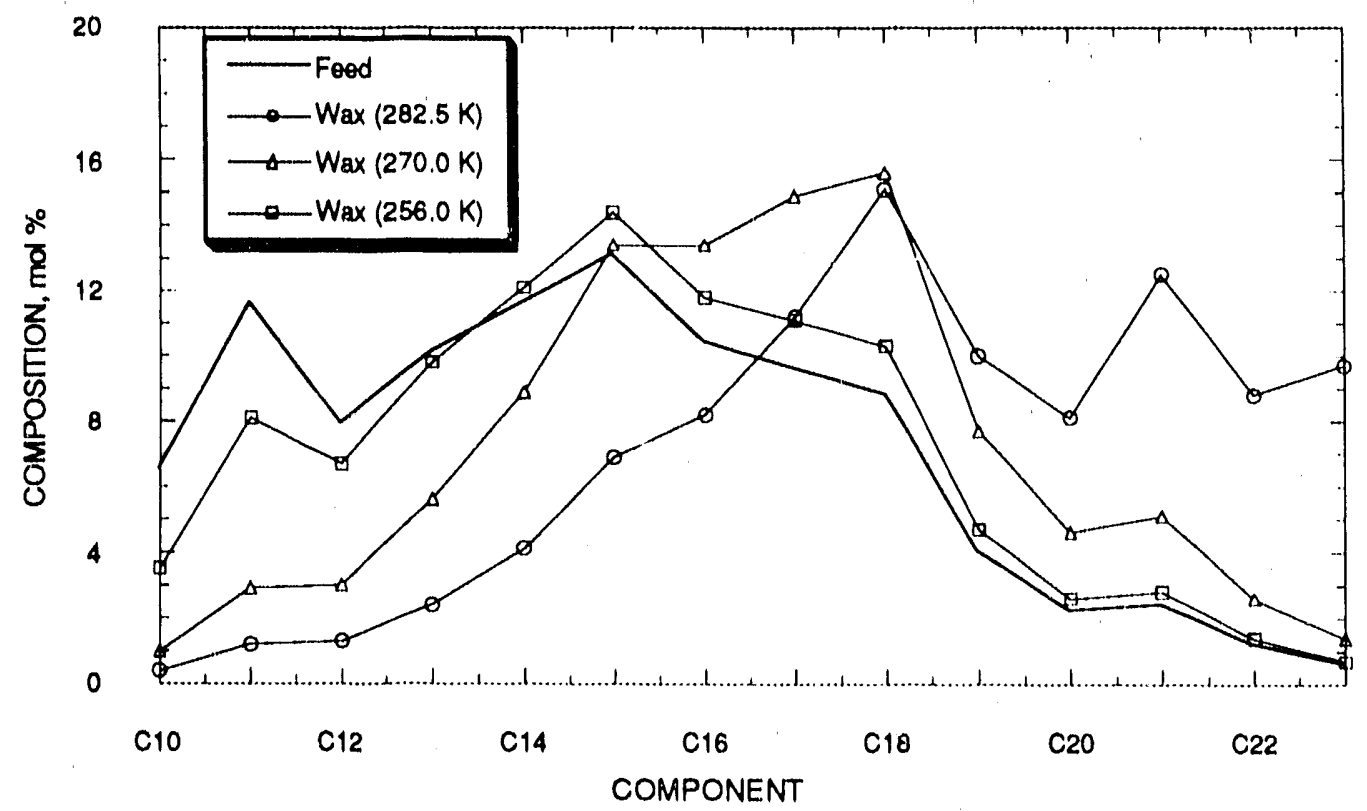

FIGURE 7. - Composition distributions for waxes and original oil. 


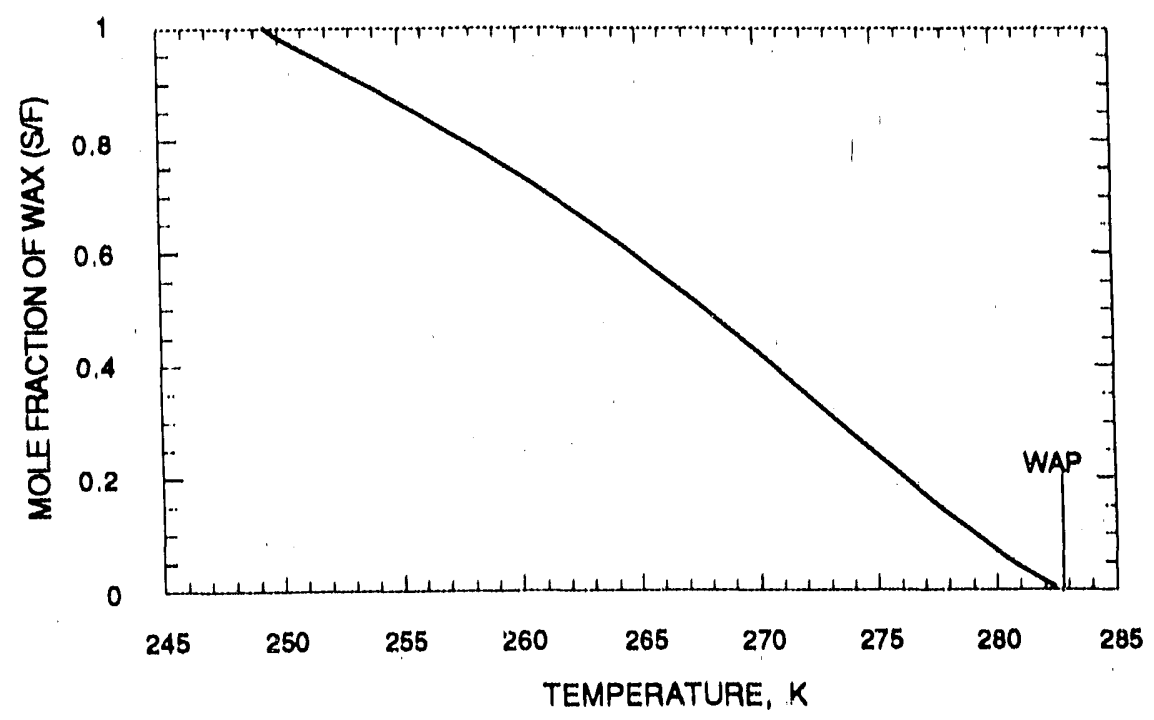

FIGURE 8. - Amount of wax precipltation at various temperatures.

\section{RESULTS AND CONCLUSIONS}

1. A simplified asphaltene solubility model based on polymer solution theory was developed and tested. The model is able to predict qualitatively the following reported trends for a typical case:

- Asphaltene solubility initially decreases with increases in pressure and reaches a minimum near the bubble point. Above the bubble point, the solubility increases with increases in pressure.

- At a given pressure, the asphaltene solubility increases with decreases in temperature.

- The composition of the reservoir fluid significantly affects asphaltene solubility. For the case studied, asphaltene solubility increases with the increase in the concentration of heavy ends at a given $P$ and $T$.

2. A thermodynamic model which includes the contributions of enthalpy and entropy was proposed for the wax-oll-phase equilibrium. The model is simple and can give a satisfactory prediction for the wax appearance temperature.

3. Samples obtained from well tubing and casing show that deposit materials contain asphaltenes, resins, wax, oil, water, and solids. Also, wax formation may induce asphaltene deposition. The variety of deposit materials and their relationship will complicate the modeling of the organic deposition.

4. Asphaltene precipitation depends on the amount and type of solvent used. The precipitate decreases with the increase of n-paraffin (solvent) carbon number. 
5. A sequential precipitation procedure, for example, using $n C_{5}$ followed by $n C_{7}$, increases the precipitate over that obtained by using only one solvent, $;$ for example, $\mathrm{nC}_{7}$.

6. The molecular weight, atomic $\mathrm{H} / \mathrm{C}$ ratlo, and sulfur content of the precipltated asphaltene vary with solvents.

7. Because the physical and chemical properties of asphaltenes in solution are not well known, asphaltene characterization is still intractable.

8. The solubility of asphaltene in oll is not totally reversible. However, the solubility of asphaltene in some solvents such as toluene is reversible. These two different behaviors become a problem for modeling.

9. Adding aromatic solvents in oil does not decrease the asphaltene precipltation by n-paraffin titration.

\section{NOMENCLATURE}

a)

a $=$ activity of the component 'i'

a

aij

A

$b_{i}$

b

B

$\mathrm{C}_{7+}$

$\left(\Delta C_{p}\right)$

$f_{i}$

$f_{p}^{i}$

$\mathrm{i}_{\mathrm{T}}^{\mathrm{i}}$

$f_{v}^{i}$

$\mathrm{F}^{\mathrm{SL}}$

$\Delta G^{E}$

$\Delta G^{M}$

$\left(\Delta H_{i}\right)_{T}$

$\left(\Delta H_{i}\right)_{T B}$ deflned by equation 1.43 defined by equation 1.44
$=$ critical pressure, critical temperature and acentric factor dependent equation of state parameter for component $i$, defined by equation 1.34

$=$ equation of state parameter for the mixture; defined by equation 1.38

$=$ equation of state parameter for the mixture; defined by equation 1.39

= pressure, temperature and composition dependent equation of state parameter;

$=$ critical pressure and critical temperature dependent equation of state parameter for component ' $\mathrm{l}$ '; defined by equation 1.37

$=$ equation of state parameter for the mixture; defined by equation 1.40

= pressure, temperature and composition dependent equation of state parameter;

$=$ symbol for describing heptane and heavier components in the feed

$=$ difference in molar heat capacity of component $i$ between liquid and solid state

$=$ fugacity of component $i$, defined by equation 1.42

$=$ coefficient defined by equation 1.29

$=$ coefficient defined by equation 1.23

$=$ coefficient defined by equation 1.26

= function, defined by equation 2.20

$=$ change in excess Gibb's free energy; defined by equation 2.17

$=$ change in Gibb's free energy due to mixing, defined by equation 2.13

$=$ heat of vaporization of component $i$ at temperature ' $T$ '; defined by equation 1.55

$=$ heat of vaporization of component $i$ at normal boiling point TB; defined by equation 1.56 


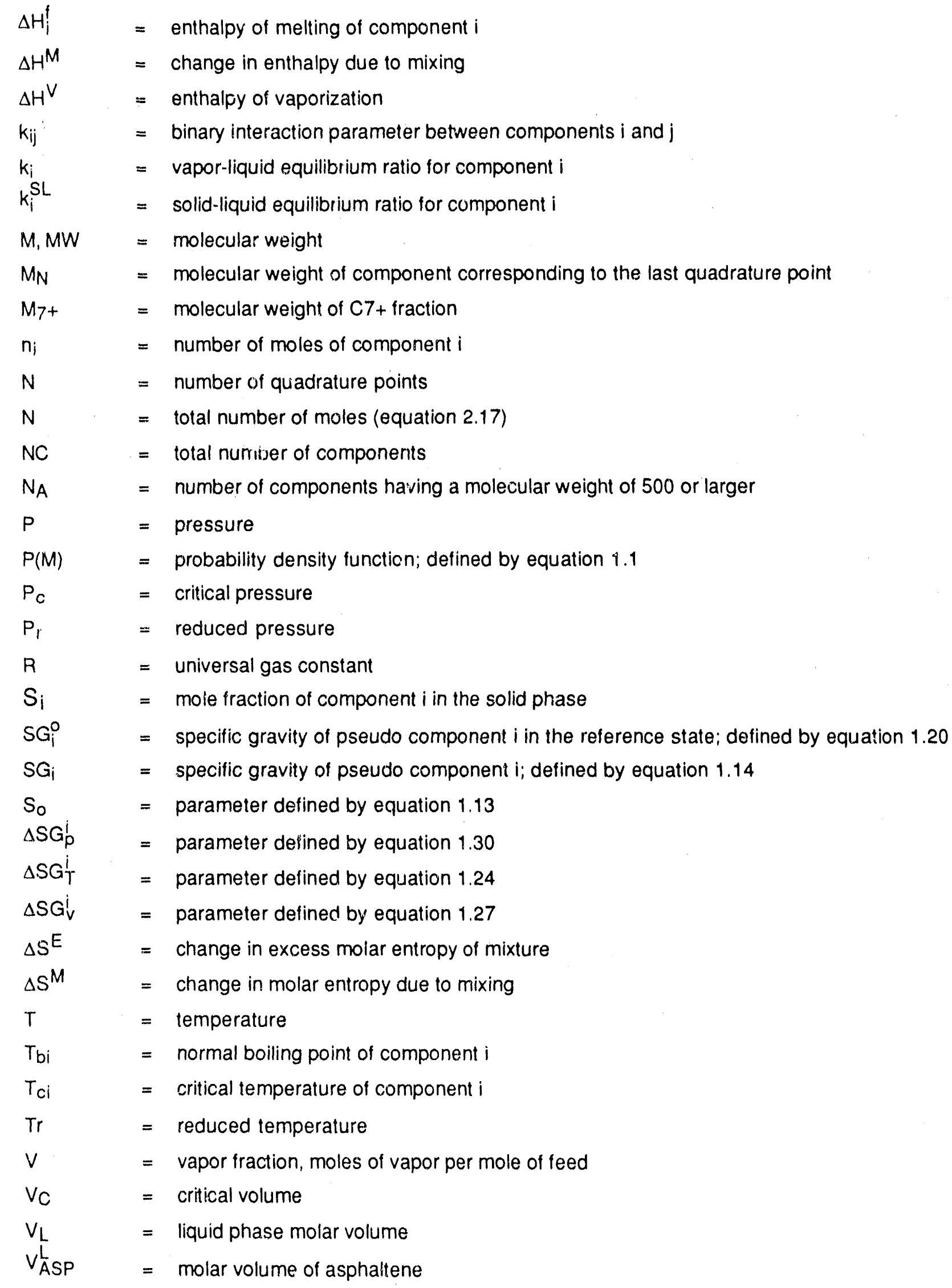




$$
\begin{array}{ll}
V_{i}^{L} & =\text { molar volume of component } i \text { in the liquid phase } \\
V_{s}^{L} & =\text { molar volume of asphaltene-free oil } \\
W_{i} & =\text { weighing factor for the ith quadrature point } \\
x_{i} & =\text { mole fraction of ith component in the liquid phase } \\
X_{i} & =\text { ith quadrature point } \\
y_{i} & =\text { mole fraction of ith component in the vapor phase } \\
Z_{i} & =\text { mole fraction of ith component in the feed } \\
Z_{7+} & =\text { mole fraction of } C_{7+} \text { frqaction in the feed } \\
z & =\text { compressibility factor }
\end{array}
$$

\section{Greek Symbols}

$\alpha$

$\beta$

$\gamma \psi$

$\gamma_{i}^{s}$

$\Gamma(\xi)$

$\delta_{i}$

$\bar{\delta}$

$\delta_{\text {Asp }}$

$\delta_{s}$

$\eta$

8

$\lambda_{i}$

$\checkmark$

$\xi_{\mathrm{i}}$

$\sigma$

$\phi_{\mathrm{i}}$

$\Phi$

$\left(\Phi_{A S P}\right)_{\max }$

$x_{i j}$

$w_{i}$
$=$ coefficient, defined by equation 1.21

$=$ coefficient, defined by equation 1.15

= activity coefficient of component $i$ in the liquid phase

$=$ activity coefficient of component $i$ in the solid phase

= gamma distribution function

= solubility parameter for component $i$

= average solubility parameter of mixture defined by equation 2.7

= solubility parameter for asphaltene; defined by equation 1.65

= solubility parameter for solvent; defined by equation 1.64

- minimum molecular weight with non zero prbability of occurrence

= distribution parameter, defined by equation 1.2

= equation of state parameter, defined by equation 1.35

= pseudo component characterization factor; defined by equation 1.12

= carbon number of component $\mathrm{i}$

$=$ a distribution parameter that defines the form of gamma distribution

$=$ fugacity coefficient of component $\mathrm{i}$

- volume fraction of component $\mathrm{i}$

= maximum volume fraction of asphaltene soluble in the crude; defined by equation 1.67

$=$ binary interaction parameter between component $i$ and $j$, defined by equation 2.16

$=$ acentric factor for component $i$; defined by equation 1.31 


\section{REFERENCES}

1. Thaver, R., D. C. Nicoll, and G. Dick. Asphaltene Deposition in Production Facilities. Pres. at the SPE Oilfield Chemistry Int'I Symp., Houston, TX, Feb. 8-10, 1989. SPE paper 18473.

2. Leontaritis K. J. and G. A. Mansoori. Asphaltene Deposition: A Survey of Field Experiences and Research Approached. J. Pet. Sci. Eng., v. 1 No. 3, 1988, pp. 229-239.

3. Monger, T. G. and J. C. Fu. The Nature of $\mathrm{CO}_{2}$-Induced Organic Deposition. Pres. at SPE Annual Tech. Conf. and Exhibition, Dallas, TX. Sept. 27-30, 1987. SPE paper 16713.

4. Mansoori, G. A. and T. S. Jiang. Asphaltene Deposition and its Role in EOR Gas Flooding Process. Proc., The 3rd European Meeting on Improved Oil Recovery, Rome, Italy, April 1985.

6. Tuttle, R. N. High Pour-Point and Asphaltic Crude Oils and Condensates. J. Pet. Tech., June 1983, pp. 1192-1196.

7. Lichaa, P. M. Asphaltene Deposition Problem in Venezuela Crudes - Usage of Asphaltenes in Emulsion Stability. Oil Sands, 1977, pp. 609-624.

8. Haskett, C. E. and M. Tartera. A practical Solution to the problem of asphaltene Deposits- Hassi Messaoud Field, Algeria. J. Pet. Tech., April 1965, pp. 387-391.

9 Yen, T. F., J. G. Erdman, and S. S. Pollack. Investigation of the Structure of Petroleum Asphaltenes by X-ray Diffraction. Anal. Chem., v. 33, No. 11, October 1961, pp. 1587-1594.

10. Ravey, J. C., G. Ducouret and D. Espinat. Asphaltene Macrostructure by Small Angle Neutron Scattering. Fuel, v. 67, November 1988, pp. 1560-1567.

11. Hirschberg, A., L. N. J. deJong, B. A. Schipper, and J. G. Meijer. Influence of Temperature and Pressure on Asphaltene Flocculation. Soc. Pet. Eng. J., June 1984, pp. 283-293.

12. Koots, J. A. and J. G. Speight. Relation of Petroleum Resins to Asphaltenes. Fus! ‥ 54, July 1975, pp. 179-184.

13. Nelson, W. L. Petroleum Refinery Engineering. McGraw-Hill Book Co., Nuw York, 1958.

14. Lichaa, P. M. and L. Herrera. Electrical and Other Effects Related to the Formation and Prevention of Asphaltene Deposition. Soc. Pet. Eng. of AIME, 1975. Paper 5304.

15. Leontaritis, K. J. Asphaltene Deposition: A Thermodynamic-Colloidal Model. Ph.D. Dissertation, Univ. of Illinois at Chicago, 1988.

16. Monger, T. G. The Impact of Oil Aromaticity on $\mathrm{CO}_{2}$ Flooding. Soc. Pet. Eng. J., December 1985, pp. 865-874.

17. Danesh, A., D.Krinis, G. D. Henderson, and J. M. Peden. Asphaltene Deposition in Miscible Gas Flooding of Oil Reservoirs. Chem. Eng. Res. Des., v. 66, July 1988, pp. 339-344.

18. Hansen, P. W.. A CO2 Tertiary Recovery Pilot - Little Creek Field, Mississippi. Pres. at the SPE Annual Fall Tech. Conf. and Exhibition, Denver, CO., Oct. 9-12, 1977. SPE paper 6747.

19. Collins, S. H. and J. C. Melrose. Adsorption of Asphaltenes and Water on Reservoir Rock Minerals. Pres. at SPE Oilfield and Geothermal Chemistry Int'I Symp., Denver, CO., June 1983. SPE paper 11800 .

20. Zhang, Y. F., C. G. Liu and W. J. Liang. Study of Asphaltenes in Two Chinese Asphalts by $X$ Ray Diffraction. Fuel Sci. \& Tech. Int'I, v. 7, No. 7, 1989, pp. 919-929. 
21. Dwiggins, C. W. Study of the Colloidal Nature of Petroleum with an Automated Bonse-Hart XRay Small-Angle Scattering Unit. Appl. Cryst., v. 11, 1978, pp. 615-619.

22. Dickie, J. P. and T. F. Yen. Macrostructures of the Asphaltic Fractions by Various Instrumental Methods. Anal. Chem. v. 39, 1967, p. 1847.

23. Dickie, J. P., M. N. Haller and T. F. Yen. Electron Microscopic Investigations on the Nature of Petroleum Asphaltenes. J. Colloid Interface Sci., v. 29, 1969, pp. 475-484.

24. Yen, T. F., J. W. Burger and N. C. LI. Chemistry of Asphaltenes. v. 195, ACS, Washington, D.C., 1981, pp. 37-51. 1980.

25. Speight, J. G. in The Chemistry and Technology of Petroleum. Marcel Dekker Inc., New York,

26. Ray, B. R., P. A. Witherspoon and R. E. Grim. A Study of the Colloidal Characteristics of Petroleum Using the Ultracentrifuge. J. Phys. Chem., v. 61, 1957, pp. 1296-1302.

27. Overtield, R. E., E. Y. Sheu, S. K. Sinha, and K. S. Liang. SANS Study of Asphaltene Aggregation. Pres. at the ACS Sym. on Characterization and Chemistry of Tar Sand, Torcnto, Canada, June 1988, pp. 308-313.

28. Leontaritis, K. J. and G. A. Mansoori. Asphaltene Flocculation during Production and Processing: A Thermodynamic-Colloidal Model. Pres. at SPE Oilfield Chemistry Int'l. Symp., Richardson, TX, 1987. SPE paper 16258.

29. Leontaritis, K. J. and G. A. Mansoori. Fast Crude-Oil Heavy-Component Characterization Using Combination of ASTM, HPLC, and GPC Methods. J. Pet. Sci. and Eng., v. 2, 1988, pp. 1-12.

30. Burke, N. E., R. D. Hobbs and S. F. Kashou. Measurement and Modeling of Asphaltene Precipitation from Live Reservoir Fluid Systems. Pres. at the SPE Annual Tech. Conf. and Exhibition, Houston, TX, Oct. 2-5, 1988. SPE paper 18273.

31. Cotterman, R. L. and J. M. Prausnitz. Flash Calculation for Continuous or Semicontinuous Mixtures Using an Equation of State. Ind. Eng. Chem. Process Des. Dev., v. 24, 1985, pp. 434-443.

32. Due, P. C. and G. A. Mansoori. Continuous Mixture Computational Algorithm of Reservoir Fluids Phase Behavior Applicable for Compositional Reservoir Simulation. Pres. at SPE Eastern Regional Meeting, Columbus, Ohio, Nov. 12-14, 1986. SPE paper 15953.

33. Peng, D. Y. and D. B. Robinson. A New Two-Constant Equation of State. Ind. Eng. Chem. Fundamental, v. 15, No.1, 1976, pp. 59-64.

34. Hong, K. C. Lumped-Component Chiaracterization of Crude Oils for Compositional Simulation. Pres. at the 3rd SPE/DOE Symp. on EOR, Tuisa, OK, Apr. 4-7,1982. SPE/DOE paper 10691.

35. Grigg, R. B. and P. J. Lingane. Predicting Phase Behavior of Mixtures of Reservoir Fluids with Carbon-dioxide. Pres. at the SPE Annual Tech. Conf. and Exhibition, San Francisco, CA, Oct. 5-8, 1983. SPE paper 11960.

36. Lee, S. T., R. H. Jacoby, W. H. Chen and W. E. Culham. Experimental and Theoretical Studies on the Fluid Properties Required for Simulation of Thermal Processes. Soc. Pet. Eng. J. v. 21, October 1981, pp. 535-550.

37. Whitson, C. H. Characterizing Hydrocarbon Plus Fractions. Soc. Pet. Eng. J., v. 23, August 1983, pp. 683-694. 
38. Cotterman, R. L., R. Bender and J. M. Prausnitz. Phase Equilibria for Mixtures Containing Very Many Components - Development and Application of Continuous Thermodynamics for Chemical Process Design. Ind. Eng. Chem. Proc. Des. Dev., v. 24, No. 2, 1985, pp. 194-203.

39. Behrens, R. A. and S. I. Sandler. The use of Semicontinuous Description to Model the $\mathrm{C}_{7+}$ Fractions in Equation of State Calculations. Pres. at the 5th SPE/DOE Sym. on EOR, Tulsa, OK, April 2023, 1986. SPE/DOE paper 14925.

40. Whitson, C. H., T. F. Anderson and I. Soreide. $C_{7}+$ Characterization of Related Equilibrium Fluids Using Gamma Distribution. in $C_{7}+$ Fraction Characterization, ed. by L.G. Chorn, and G.A. Mansoori, Taylor \& Francis, New York, 1989, pp. 35-56.

41. Stroud, A. H. and D. Secrest. Gaussian Quadrature Formulas, Prentice-Hall, Englewood Cliffs, N.J., 1966.

42. Abramowitz, M. and I. A. Stegun. Handbook of Mathematical Functions. Nat'l Bureau of Standards, Washington, D.C., 1964.

43. Twu, C. H.. An Internally Consistent Correlation for Predicting Critical Properties and Molecular Weights of Petroleum and Coal-Tar Liquids. Fluid Phase Equil., v. 16, 1984, pp. 137-150.

44. Chung, T. H. Characterization and Thermophysical Property Predictions for Petroleum Fractions. $C_{7}+$ Fraction Characterization. ed. by L.G. Chorn and A.G. Mansoori, Taylor \& Francis, New York , 1989, pp. 153-165.

45. Edmister, W. C. Compressibility Factors and Equation of State. Petroleum Refiner, v. 37, No. 4, 1958, pp. 173-179.

46. Prausnitz, J. M. Molecular Thermodynamics of Fluid Phase Equilibria. Prentice-Hall Inc., Englewood Cliffs, N.J., 1969.

47. Gambill, W. R. Determine Heat of Vaporization. Chem. Eng., v. 64, No. 12, December 1957 , pp. 261-266.

48. Won, K. W. Thermodynamics for Solid Solution-Liquid-Vapor Equilibria: Wax Phase Formation from Heavy Hydrocarbon Mixtures. Fluid Phase Equil., v. 30, 1986, pp. 265-279.

49. Hansen, J. H., A. Fredenslund, K. S. Pedersen, and H. P. Ronningsen. A Thermodynamic Model for Predicting Wax Formation in Crude Oils. AlChE J., v. 34, No. 12, December 1988, pp. 1937. 1942.

50. Flory, P. J. Principles of Polymer Chemistry, Cornell Univ. Press, Ithaca, NY, 1953.

QU.S. COVERNMENT PUINTINC OFFICE: 1990.561 .02920063 

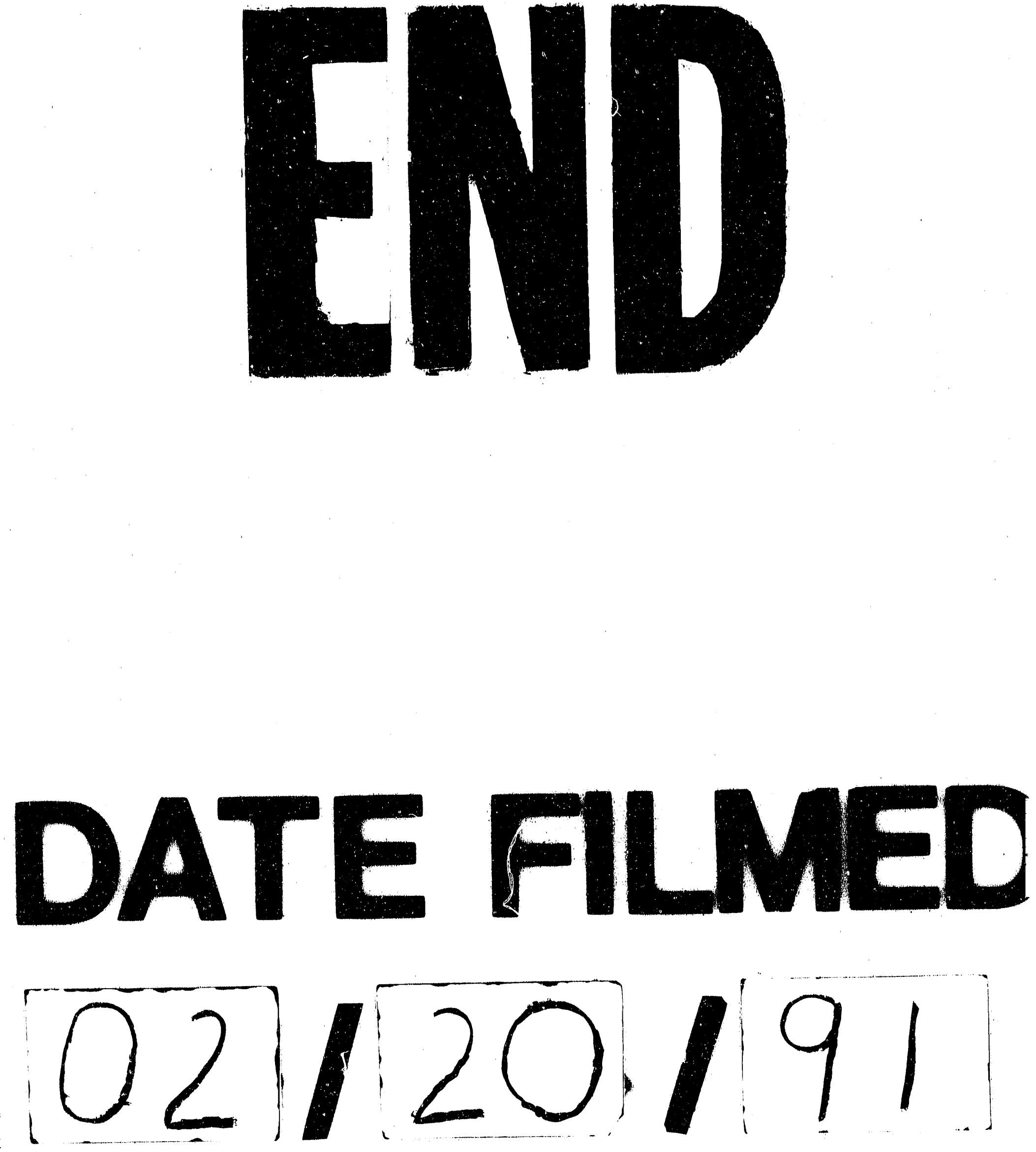
